\title{
Computational Analysis of the Effect of Porosity on Shock Cell Strength at Cruise
}

\author{
Steven J. Massey* \\ Eagle Aeronautics, Inc., Hampton, VA 23669, USA
}

Alaa A. Elmiligui ${ }^{\dagger}$

Analytical Services \& Materials Inc., Hampton, VA 23666, USA

\author{
Russell H. Thomas $\underset{\ddagger}{\ddagger}$ S. Paul Pao \\ NASA Langley Research Center, Hampton, VA 23681, USA
}

\begin{abstract}
A computational flow field analysis is presented of the effect of core cowl porosity on shock cell strength for a modern separate flow nozzle at cruise conditions. The goal of this study was to identify the primary physical mechanisms by which the application of porosity can reduce shock cell strength and hence the broadband shock associated noise. The flow is simulated by solving the asymptotically steady, compressible, Reynoldsaveraged Navier-Stokes equations on a structured grid using an implicit, up-wind, flux-difference splitting finite volume scheme. The standard two-equation $k-\varepsilon$ turbulence model with a linear stress representation is used with the addition of a eddy viscosity dependence on total temperature gradient normalized by local turbulence length scale. Specific issues addressed in this study were the optimal area required to weaken a shock impinging on the core cowl surface and the optimal level of porosity and placement of porous areas for reduction of the overall shock cell strength downstream. Two configurations of porosity were found to reduce downstream shock strength by approximately $50 \%$.
\end{abstract}

\section{Introduction}

The principal components of supersonic jet noise for imperfectly expanded jets are turbulent mixing noise, broadband shock associated noise and screech tones. The focus of this study is the sources relevant to broadband shock associated noise, which is a major source of noise within the cabin of a typical passenger airliner. Shock-cell noise propagates onto the fuselage at frequencies from 20 to $2000 \mathrm{~Hz} .{ }^{1}$ In the aft cabin at cruise conditions, shock-cell noise can be the primary source of noise. One reason that broadband shock associated noise has become more prominent is due to reductions in other sources of noise. Reducing fuselage weight or the addition of other technologies can have unintended acoustic consequences if not addressed and mitigated. Long ${ }^{2}$ measured the effects of three separate flow chevron configurations relative to an axisymmetric baseline nozzle at model scale at several operating conditions including cruise and found that the effects of chevrons were not always favorable to shock cell noise in spite of benefits to community noise levels at takeoff and landing. To meet increasingly stringent workplace noise regulations and to insure passenger comfort, a significant amount of insulation can be required to attenuate shock-cell noise. The resultant weight increase directly translates to increased fuel costs and decreased payload capacity.

Harper-Bourne and Fisher ${ }^{3}$ produced the first quantitative model of broadband shock associated noise and found experimentally that the strength of the radiated noise was directly proportional to the pressure difference across the mean shock waves of the jet. Pao and Seiner ${ }^{4}$ extended the Harper-Bourne and Fisher theory to both cold and hot jets by using a generalized Helmholtz number for the correlation parameter of shock noise peak frequency. Abdol-Hamid and Wilmoth ${ }^{5}$ demonstrated the importance of turbulence models in shock cell computations. Bent et al. ${ }^{6}$ measured

\footnotetext{
*Senior Research Scientist, s.j.massey@larc.nasa.gov, 13 West Mercury Blvd., AIAA Member.

$\dagger$ Senior Scientist, 107 Research Dr., AIAA Member.

${ }^{\ddagger}$ Senior Research Engineer, Aeroacoustics Branch, MS 166, Senior Member AIAA

$\S$ Senior Research Engineer, Configuration Aerodynamics Branch, MS 499, Associate Fellow AIAA

I Aerospace Engineer, Configuration Aerodynamics Branch, MS 499, Associate Fellow AIAA

${ }$ Aerospace Engineer, Configuration Aerodynamics Branch, MS 499
} 
shock cell noise of a separate flow nozzle at aircraft engine temperatures and pressures, with a free stream Mach limited to 0.32 . A survey of supersonic jet noise is provided by Tam. ${ }^{7}$

In this study, several porous cowl configurations and one porous pylon are evaluated on a modern high bypass ratio separate flow nozzle at cruise conditions for their efficacy in reducing the amplitude of the shock cell pressure waves. Porosity for supersonic jet noise suppression has been under study for many years. Maestrello ${ }^{8}$ measured the effectiveness of reducing broadband shock associated noise and screech by porosity on an extended plug in single stream supersonic jets. And more recently, Gilinsky et al. ${ }^{9}$ experimentally showed appreciable jet noise reduction with the addition of a cylindrical permeable shell at the nozzle exit, again for a single supersonic jet. The type of porosity considered in this study is surface porosity that would typically be created by a perforated face sheet, flush with the surface, and a cavity below the face sheet. The implementation of

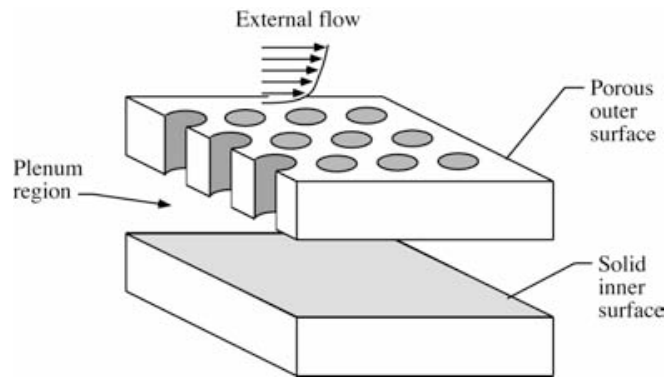

Figure 1. Crosssectional view of surface porosity. this type of porosity has been studied for many other applications, including by Hunter et al., ${ }^{10}$ for example. Figure1 from Hunter et al., ${ }^{10}$ shows the typical cross section of the surface porosity. The porous surface and the cavity below allow pressure differences across the treated surface area to equalize by communicating through the surface and cavity below through typically very small mass flows. Computationally, the surface porosity has been modeled very effectively with boundary conditions extensively in previous studies by Elmiligui et al. ${ }^{11}$ and others.

Bhat et al. ${ }^{12}$ recently conducted experiments with a model-scale axisymmetric separate flow nozzle. Results indicated a strong relationship between the amplitude of the shock-cell structures and the radiated noise. Given this proven relationship between shock cell strength and broadband shock associated noise intensity, ${ }^{3,12}$ this study will only address shock cell strength rather than the predicted noise of the shock cells.

\section{Configuration and Conditions}

The configuration that was simulated and studied in this work is that of a modern separate flow nozzle of nominal bypass ratio eight. A typical cruise condition is simulated even though only a nozzle and pylon geometry combination is considered. The cruise Mach number is 0.84 , the fan nozzle pressure ratio is 2.33 and the core nozzle pressure ratio is 1.74 . The fan to core total temperature ratio is 2.25 .

\section{Numerical Method}

The fluid flow is simulated by solving the asymptotically steady, compressible, Reynolds-averaged Navier-Stokes equations using an implicit, up-wind, flux-difference splitting finite volume scheme and standard two equation $k$ $\varepsilon$ turbulence model ${ }^{13}$ with a linear stress representation and the addition of an eddy viscosity dependence on total temperature gradient through the variation the $C_{\mu}$ closure coefficient, see Abdol-Hamid et al. ${ }^{14}$ All computations are performed using the parallel, multiblock, structured grid code PAB3D. ${ }^{15}$ Viscous diffusion terms are modeled as uncoupled in the flow direction and fully coupled in the cross-flow direction and a three-factor scheme is used for the approximation of implicit terms.

The computational domain extends six core diameters upstream from the fan exit, 30 downstream and eight radially. The axial spacing growth rate in the plume is a very low 1.01 which is required to preserve the shock cells. The aspect ratio in the center of the fan flow over the porous patch is held to one to resolve oblique shocks. Transitions from boundary to shear layer grids are smoothed to aid convergence. The average value of the law of the wall coordinate, $y^{+}$, of the first cell center is less than one on all viscous surfaces. Nozzle and plume areas of the medium level grid colored by pressure are shown in Figure 2. All plots are shown in coordinates nondimensionalized by the core exit diameter $(D)$, with the origin at the fan exit. Grid sequencing is used to accelerate convergence by solving $1 / 4$ then $1 / 2$ of the grid in each of the three computational directions. The typical iteration count for 3-D grids at each grid level is 10,000. Axisymmetric cases are stiffer and are therefore run three times longer. A sample convergence history, Figure 3, in terms of flow and turbulence residual is shown for four grid sequence levels, where the third level of refinement was used for the production runs. Typically the flow residual drops by five orders of magnitude. Pressure along the center of the fan stream from converged solutions at each of the four grid levels indicate that the third level of grid refinement, which was used for the results in this study, is fully converged in the primary shock region and accurate to within the level of interest for the shock cells in the plume, see Figure 4. 
Grid sizes range from 276,000 cells for an axisymmetric $0.6^{\circ}$ - one cell wedge grid to over 31 million cells for the full $180^{\circ}$ pylon grid. All surfaces are gridded and run as viscous with the exception of the very small tip region of the plug and the very thin nozzle trailing edges.

Typical run times for the fully converged solution at the fine grid level are less than 7 hours for 0.27 million cells using 11 3-GHz Pentium 4 nodes. Three-dimensional calculations of the half nozzle with pylon on a 31 million cell grid required 149 wall clock hours on $42 \mathrm{P} 4$ nodes. In both cases, the code runs in parallel at a speed on the order of one micro-second per iteration per cell.

\section{Results and Discussion}

This study addresses the effectiveness of porous surfaces ${ }^{11}$ to reduce shock cell strength on a modern separate flow nozzle with an isolated pylon, Figure 5. There are several potential methods for reducing shock strength including a variable nozzle that can be optimized at each cruise condition, but this is out of the scope of the present study that sought a simpler, more feasible method. The method used in this study for reducing downstream shock cell strength is to diffuse the initial shock strength at the beginning of the shock cell structure. For the subsonic cruise condition considered here the fan stream is at a higher nozzle pressure ratio than in the core stream. Therefore, the shocks are stronger in the fan stream and the initial shocks in the fan stream impinge on the core cowl region. Given that a minimum amount of porosity is desired for efficiency considerations, the first objective in this study is to demonstrate the optimal amount and placement of porosity required to diffuse the initial shock. In screening calculations, obtained with the PAB3D RANS solver on an axisymmetric version of the nozzle geometry, porosity levels of five, ten and twenty percent were considered and ten was found to be optimal. In practice, a fifteen to twenty percent level would be used to allow for blockage of individual holes from environmental factors.

\section{A. Porous Patch Length Study}

Five increasingly larger areas are evaluated on an axisymmetric grid without a pylon. Although the pylon is critical to studying the more realistic three-dimensional characteristics of the flow field, the pylon is not simulated in these screening studies in order to focus on the local physics as well as to save resources. The areas are centered around the initial shock and expand symmetrically as shown in Figure 6. Although, increased porous areas are seen to be effective at reducing near field shocks, Pressure traces through the center of the fan stream, Figure 7, indicate that the optimal area is defined by and axial range from $x_{-2}$ to $x_{2}$. This area covers the pressure "tent" formed by the shock, as shown by the light blue and green areas in Figure 6. More narrow areas reduce the communication between the sides of the shock and larger areas retard the communication by incorporating more distant low pressure areas. Pressure plots show the potential for porosity in the solid case, and the effects of porosity in the porous cases, see Figures 8-9. In the solid case of Figure 8a, the initial fan shock is seen at the $x_{0}$ location, surrounded by a compression wave and expansion wave which intersect the shock at the outer fan shear layer. These waves form the base the porous area the is the most effective at reducing the shock cell amplitude in the downstream plume. The reason for this is that the $x_{-2}$ to $x_{2}$ range represents an optimum between weakening the shock at $x_{0}$ and strengthening the shocks at $x_{4}$ and the core exit. In the case of the porosity on the range of $x_{-5}$ to $x_{5}$, the shock at $x_{4}$ merges with the core exit shock, which results in an increase in shock cell amplitude over the case of porosity on the $x_{-4}$ to $x_{4}$ range. Mach and simulated Schlieren contours, Figures 10-13 are also included to complete the description of the shock structure.

\section{B. Three Dimensional Porous Patch Location}

For a porous surface shock cell reduction strategy to be successful it must be practical to implement and tolerant of the inherently three-dimensional shock structure. The porous locations are centered on a baseline patch location which can be easily implemented in hardware. Three fan porous patch configurations and one pylon porous patch are considered, shown outlined in Figure 14. Surface pressure plotted in Figure 14, demonstrates the three-dimensionality of the flow field and the local effectiveness of porosity. The three-dimensionality is in large measure a function of the presence of the engine pylon. The pylon creates a non-symmetric flow field that is evident in contours of total temperature and local Mach number, Figure 15. Also shown in black are the extraction locations of pressure data plotted in Figure 16. These plots are a further indication of the complexity of the flow field and show that as the fan stream widens going from top to bottom locations, the amplitude of the pressure traces increase. In addition, the relative amplitudes among the cases are do not change with respect to azimuthal location. In Figure 15 local Mach number of the core flow can be seen to be subsonic due to its high temperature, but its convective Mach number based on the free stream speed of sound is supersonic. In this study, a typical cruise condition at $M=0.84$ is considered 
since it is representative of the actual flight condition where broadband shock associated noise is significant. However, the true measure of effectiveness is the shock cell amplitude in the downstream area of the plume where the noise is generated. ${ }^{12}$ A centerline plot of pressure for the each of the five cases, see Figure 17, indicates that the baseline porous patch is minimally effective, while the expanded areas of the long patch and long nearly axisymmetric strip show up to a 50\% amplitude reduction. Only one location of porosity on the pylon was computed and this is not an exhaustive study. The porous pylon, while effective locally, is seen to slightly increase the amplitude of the shock cells downstream. This location was chosen from the observation that some shock cells were incident on the side of the pylon. However, only one location of porosity on the pylon was computed as an exploratory study, a more exhaustive study of porous pylon locations would have to be done.

\section{Concluding Remarks}

A Navier-Stokes flow field analysis has been presented showing the effect of core cowl porosity on shock cell strength for a modern separate flow nozzle at cruise. The primary physical mechanisms by which the application of porosity reduces shock cell strength were demonstrated to be a focused area of porosity surrounding the pressure signature of the initial fan shock and asymmetry in the porous areas to encourage phase cancellation effects in the shock cells. Of the five porous patch configurations considered, the long porous patch configuration provided the greatest reduction in shock cell pressure amplitude.

\section{Acknowledgments}

The authors gratefully acknowledge many contributions to such a complex study. Steve Bauer at NASA Langley contributed much expertise on the subject of passive porosity from a wealth of other applications. At The Boeing Company, Ulrich Ganz, Eric Nesbitt, John Premo and Ron Olsen among others at Boeing contributed to many helpful discussions on the understanding of shock cell noise and issues associated with application. The authors also acknowledge gratefully the support of the Quiet Aircraft Technology project management, Dr. Charlotte Whitfield, Aeroacoustics Branch manager, and Mr. Larry Leavitt, Configuration Aerodynamics Branch manager. This work was funded by NASA Langley through as part of the Propulsion Airframe Aeroacoustics team.

\section{References}

\footnotetext{
${ }^{1}$ Anon., "Can you hear me now?" Aerospace Engineering Magazine, Nov. 2003.

${ }^{2}$ Long, D. F., "Effect of Nozzle Geometry on Turbofan Shock Cell Noise at Cruise," AIAA Paper 2005-0998, May 2005.

${ }^{3}$ Harper-Bourne, M. and Fisher, M. J., "The Noise from Shock Waves in Supersonic Jets," AGARD-CP-131, 1974.

${ }^{4}$ Pao, S. P. and Seiner, J. M., "A Theoretical and Experimental Investigation of Shock-Associated Noise in Supersonic Jets," AIAA Paper

${ }^{5}$ Abdol-Hamid, K. S. and Wilmoth, R. G., "Multiscale Turbulence Effects in Underexpanded Supersonic Jets," AIAA Journal, Vol. 27, No. 3,

${ }^{6}$ Bent, P. H., Blackner, A. M., Newman, S. A., and Nesbitt, E. H., "Shock Associated Noise of Dual Flow Nozzles," AIAA Paper 1998-2323,

${ }^{7}$ Tam, C. K. W., “Supersonic Jet Noise,” Annu. Rev. Fluid Mech., Vol. 27, 1995.

${ }^{8}$ Maestrello, L., “An Experimental Study on Porous Plug Jet Noise Suppressor," AIAA Paper 1979-0673, March 1979.

${ }^{9}$ Gilinsky, M., Blankson, I. M., Kouznetsov, V. M., and Chernyshev, S. A., "Aeroperformance and Acoustics of the Nozzle with Permeable Shell," AIAA Paper 1999-1924, May 1999.

${ }^{10}$ Hunter, C. A., Viken, S. A., Wood, R. M., and Bauer, S. X. S., "Advanced Aerodynamic Design of Passive Porosity Control Effectors," AIAA Paper 2001-0249, Jan. 2001.

${ }^{11}$ Elmiligui, A. A., Abdol-Hamid, K. S., and Hunter, C. A., "Numerical Investigation of Flow in an Over-expanded Nozzle with Porous Surfaces," AIAA Paper 2005-4149, July 2005.

${ }^{12}$ Bhat, T. R. S., Ganz, U. W., and Guthrie, A. R., "Acoustic \& Flow-Field Characteristics of Shock-Cell Noise from Dual Flow Nozzles," AIAA Paper 2005-2929, May 2005.

${ }^{13}$ Jones, W. P. and Launder, B. E., "The Prediction of Laminarization with a Two-Equation Model of Turbulence," Int. J. Heat Mass Transf., Vol. 15, No. 2, 1972, pp. 301-314.

${ }^{14}$ Abdol-Hamid, K. S., Pao, S. P., Massey, S. J., and Elmiligui, A. A., "Temperature Corrected Turbulence Model for High Temperature Jet Flow," ASME Journal of Fluids Engineering, Vol. 126, No. 5, 2004, pp. 844-850.

${ }^{15}$ Abdol-Hamid, K. S., "Development of Three-Dimensional Code for the Analysis of Jet Mixing Problem," NASA CR 4200, 1988.
} 1981-1973, Oct. 1981. 1989, pp. 315-322. May 1998 


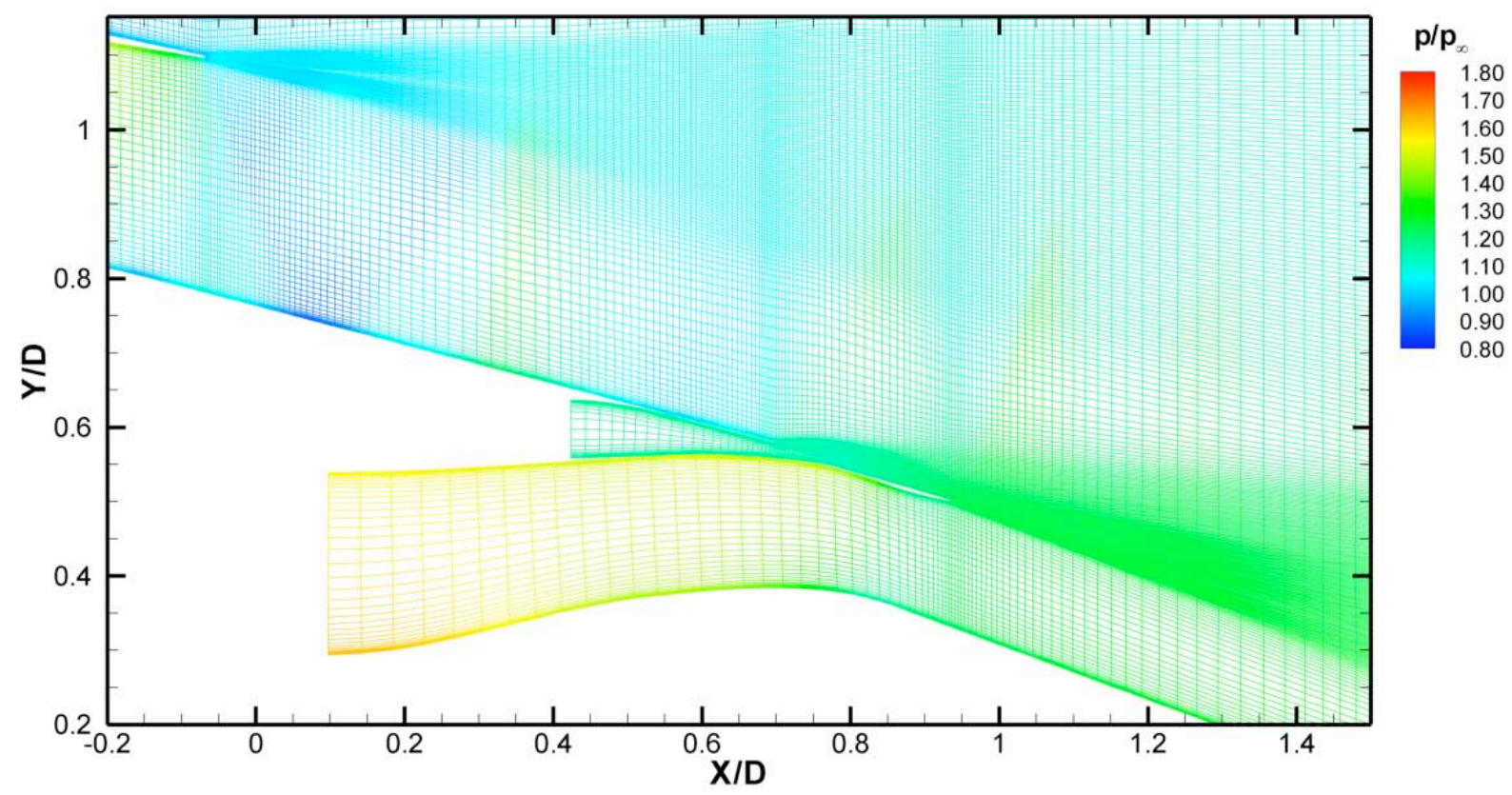

(a) Fan, Vent and Core Nozzles

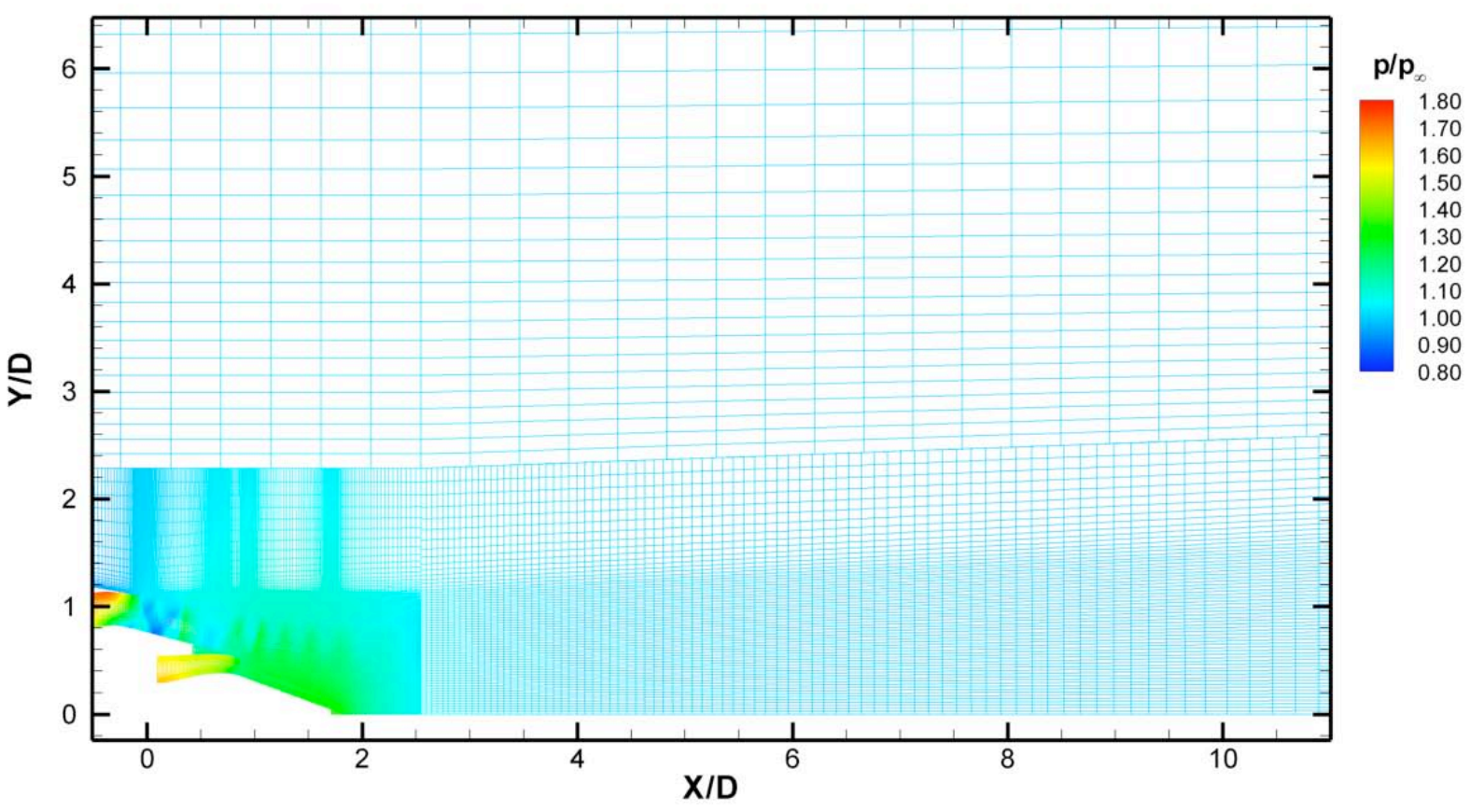

(b) Partial Plume

Figure 2. Half resolution axisymmetric grid slice colored by static pressure. 


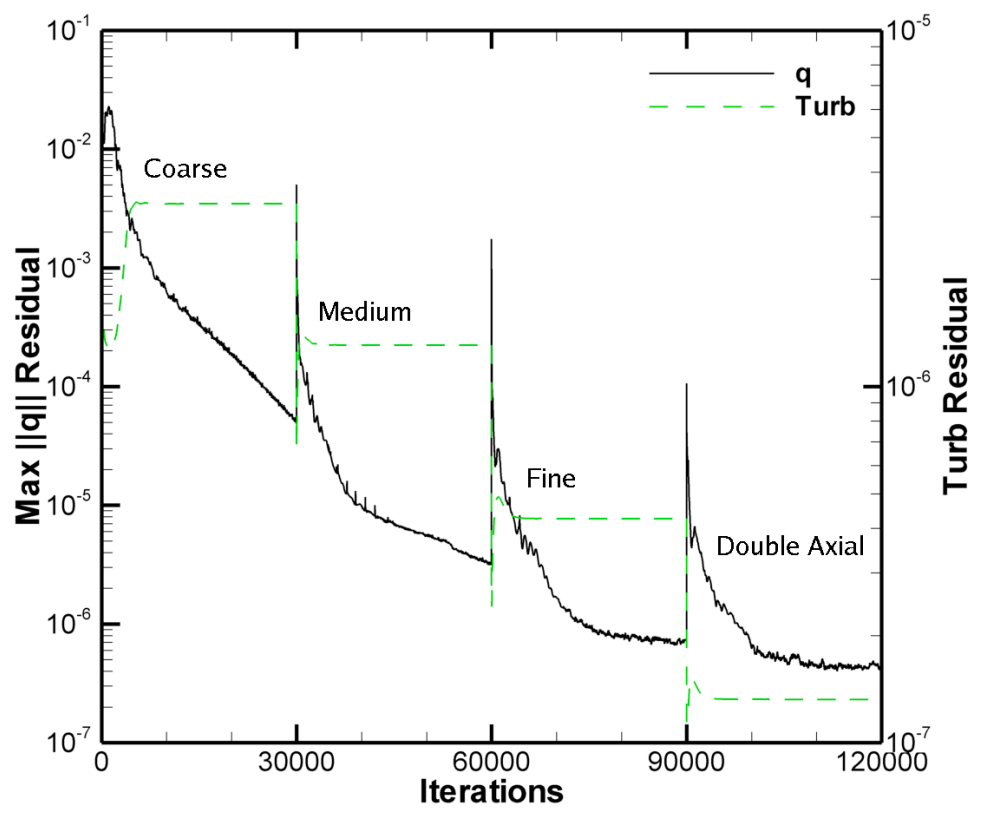

Figure 3. Convergence history of Navier-Stokes and $k-\varepsilon$ equations for four levels of grid refinement. Spikes denote the starting iteration of the grid refinements.

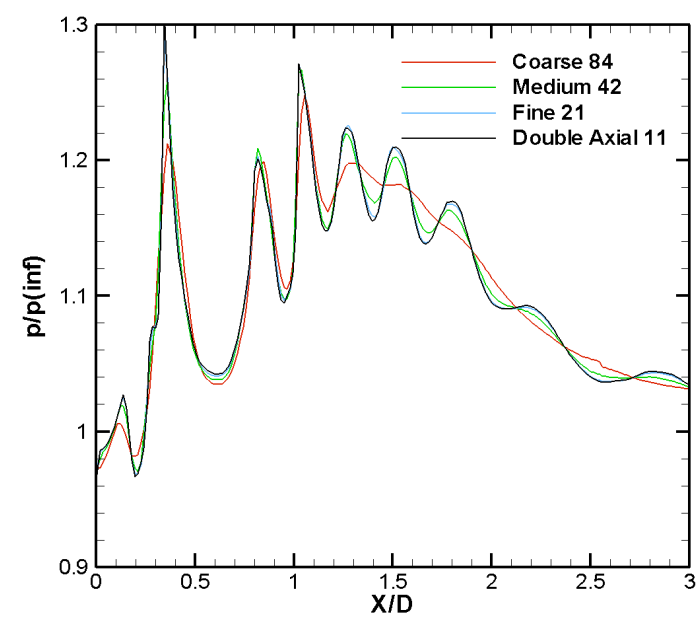

(a) Primary shocks $X / D=0$ to 3

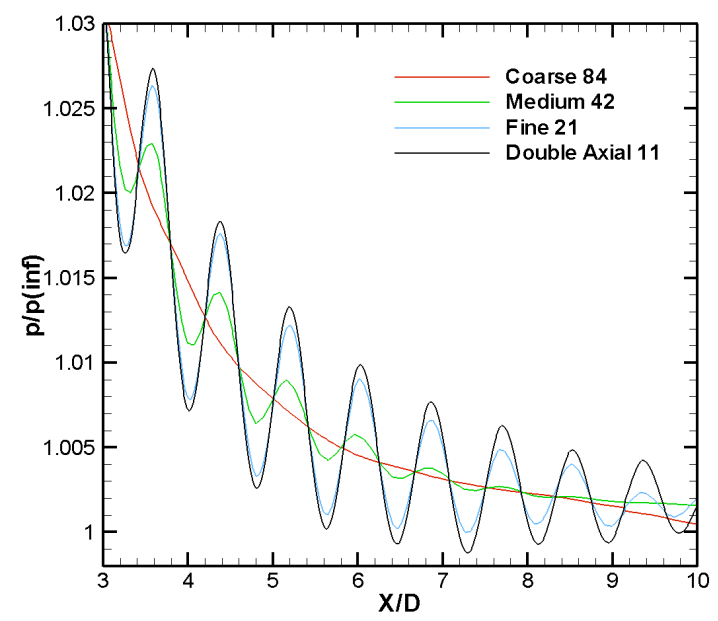

(b) Shock cells $X / D=3$ to 8

Figure 4. Grid convergence of fan primary shocks (a) and shock cells (b). From coarsest grid shown in red with the two digit code 84 to the finest with code 11, where the first digit represents the coarsening factor or cell skip in the axial direction and the second digit is the cell skip in the radial direction. 


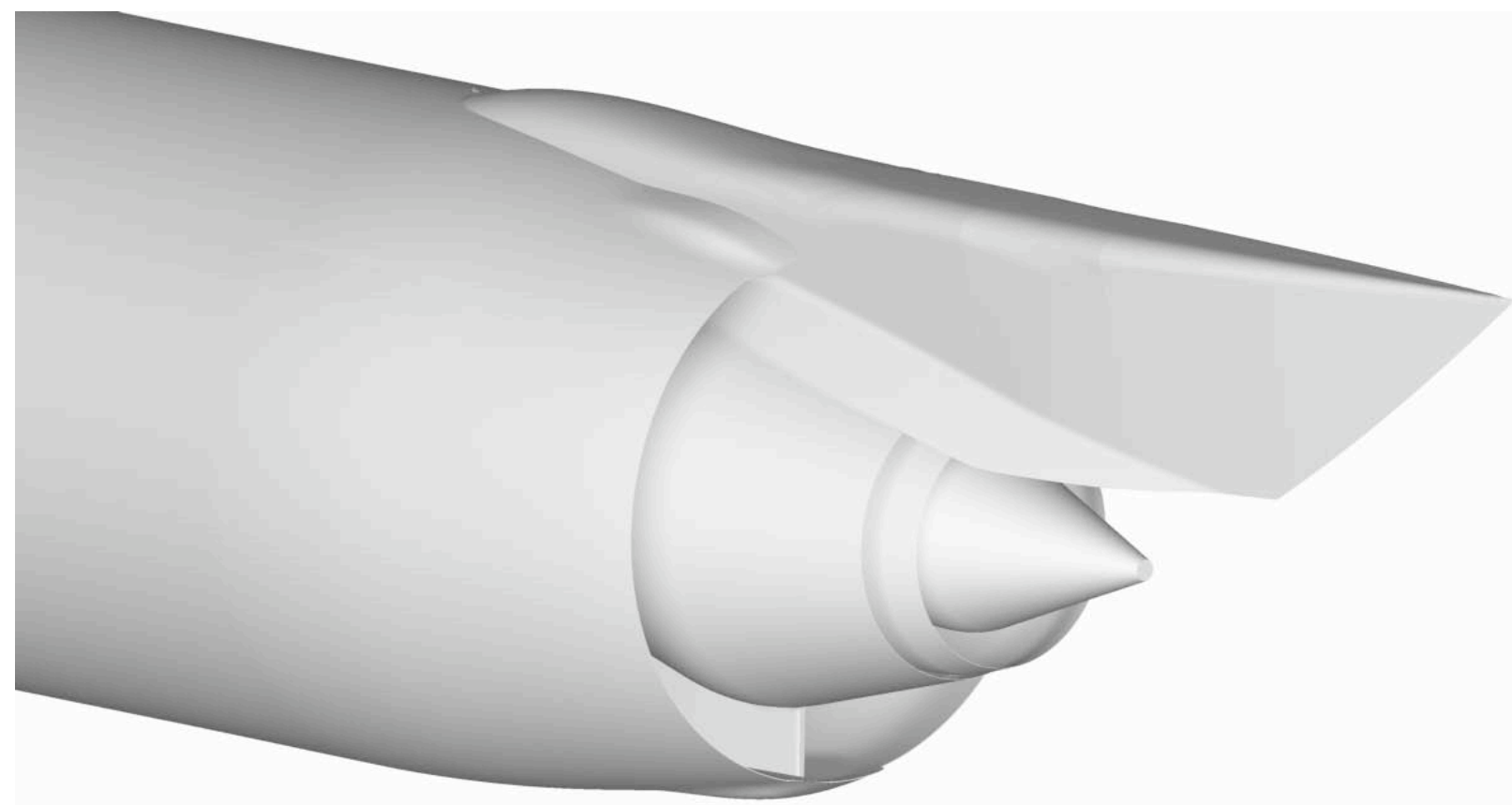

Figure 5. Separate flow nozzle including vent. Surfaces extended upstream for CFD inflow conditions.

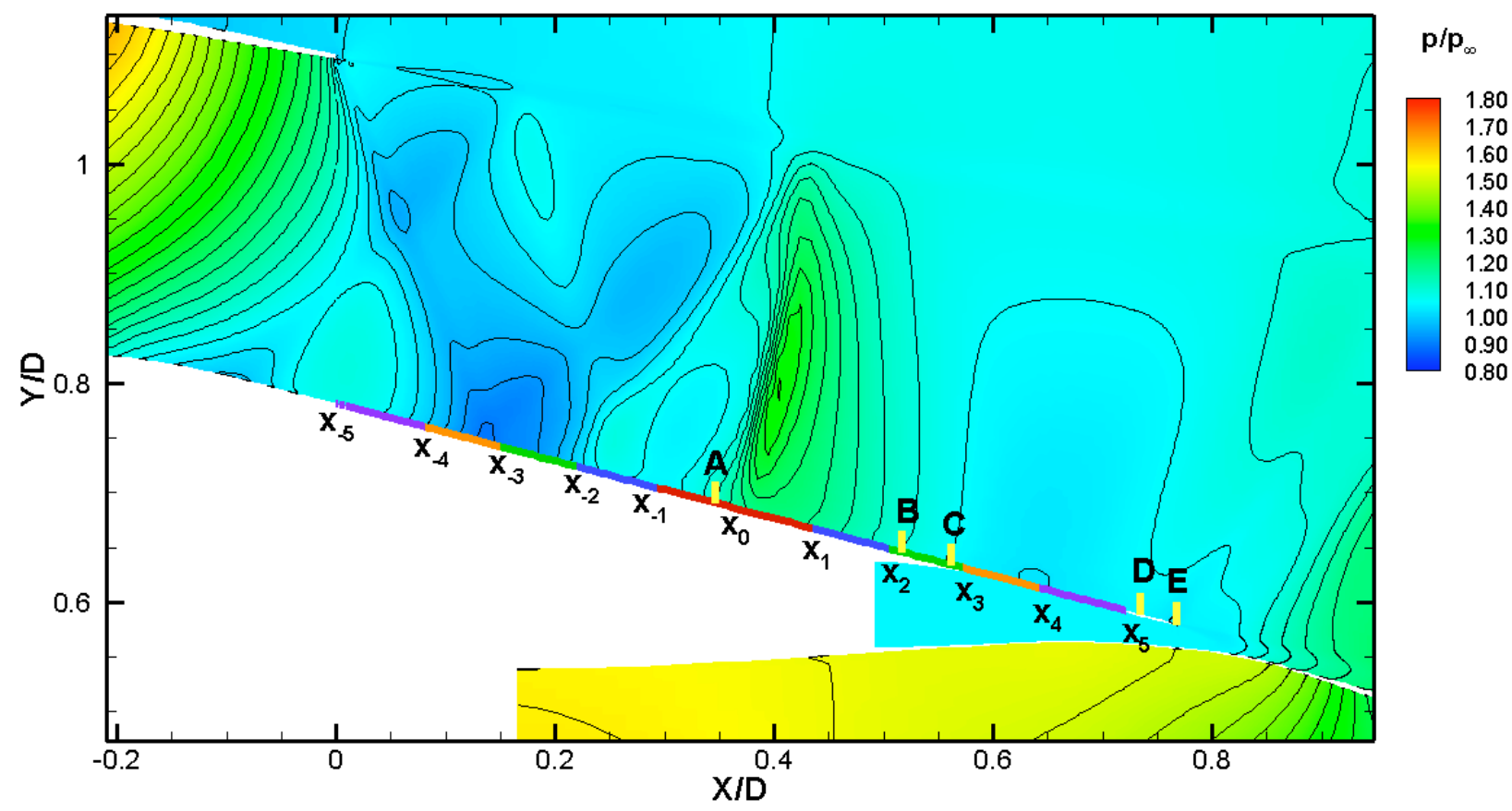

Figure 6. Normalized static pressure contours of axisymmetric solution and axial locations $\left(x_{-i}\right.$ to $\left.x_{i}\right)$ defining ranges of porosity applied to the core cowl, where $x_{0}$ is chosen to correspond to the shock. Also shown, the baseline porous patch location (AB), alternate porosity area (CD) and lower lip (E). 


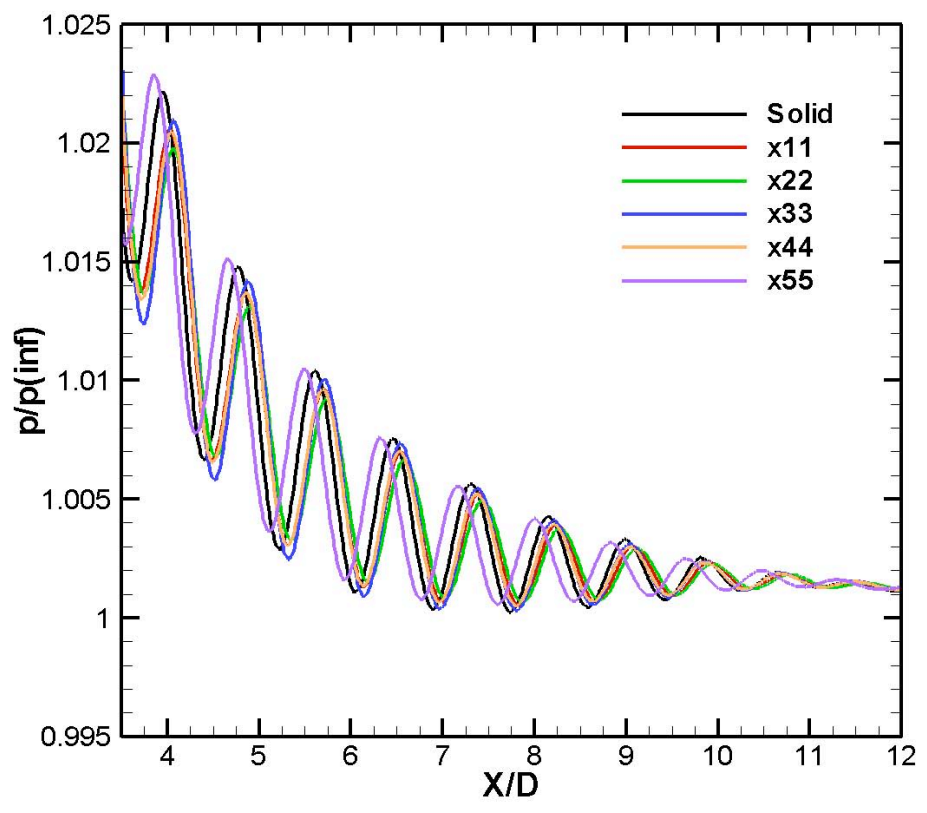

(a) $X / D=3.5$ to 12

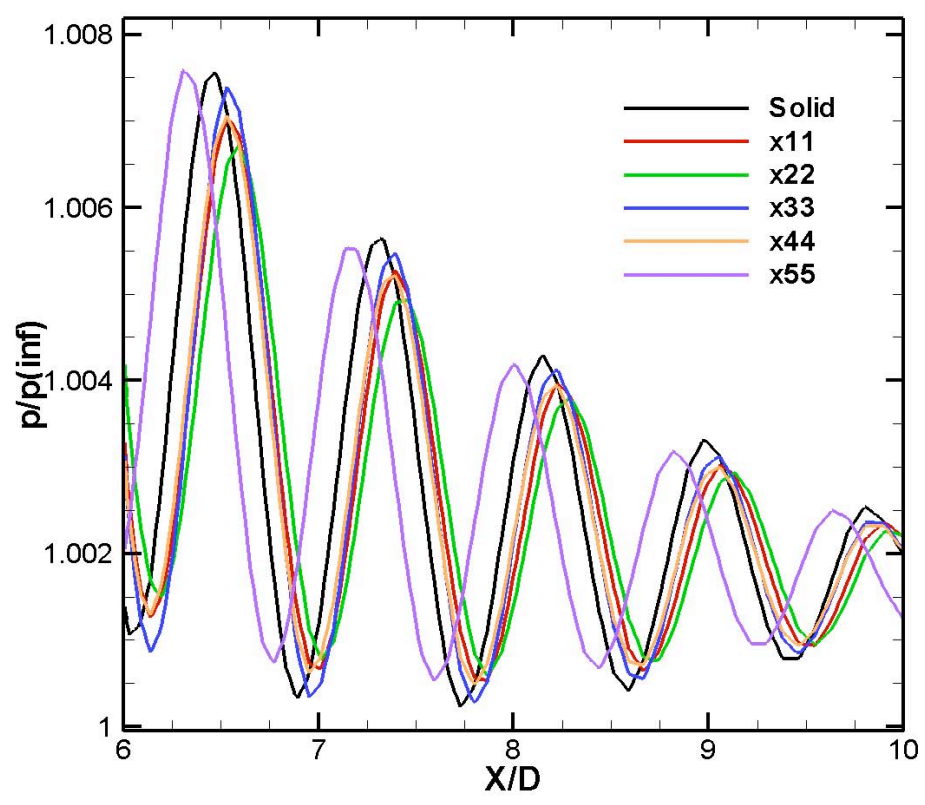

(b) $X / D=6$ to 10

Figure 7. Pressure traces through the center of the fan stream for the solid configuration and the five porosity area configurations, where $x_{i i}$ denotes porosity from $x_{-i}$ to $x_{i}$, for $i=1$ to 5 . 


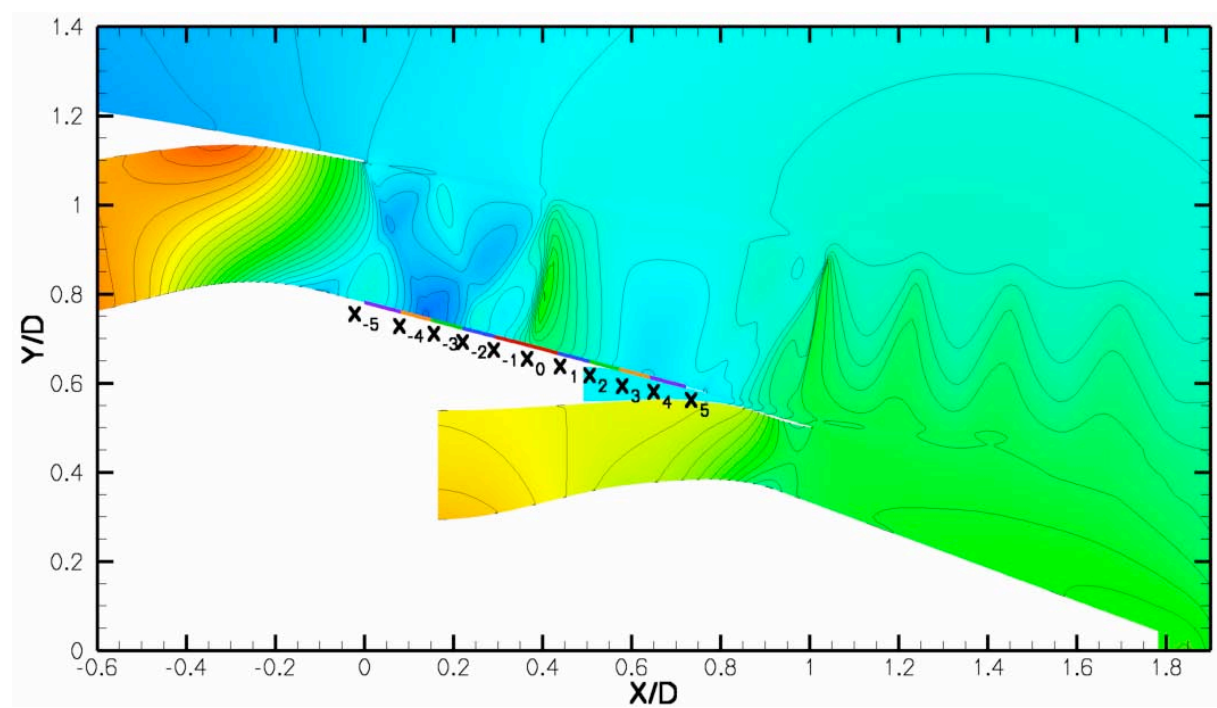

\begin{tabular}{|l}
\hline$p_{\infty} / \mathbf{p}_{\infty}$ \\
1.80 \\
1.70 \\
1.60 \\
1.50 \\
1.40 \\
1.30 \\
1.20 \\
1.10 \\
1.00 \\
0.90 \\
0.80
\end{tabular}

(a) Solid

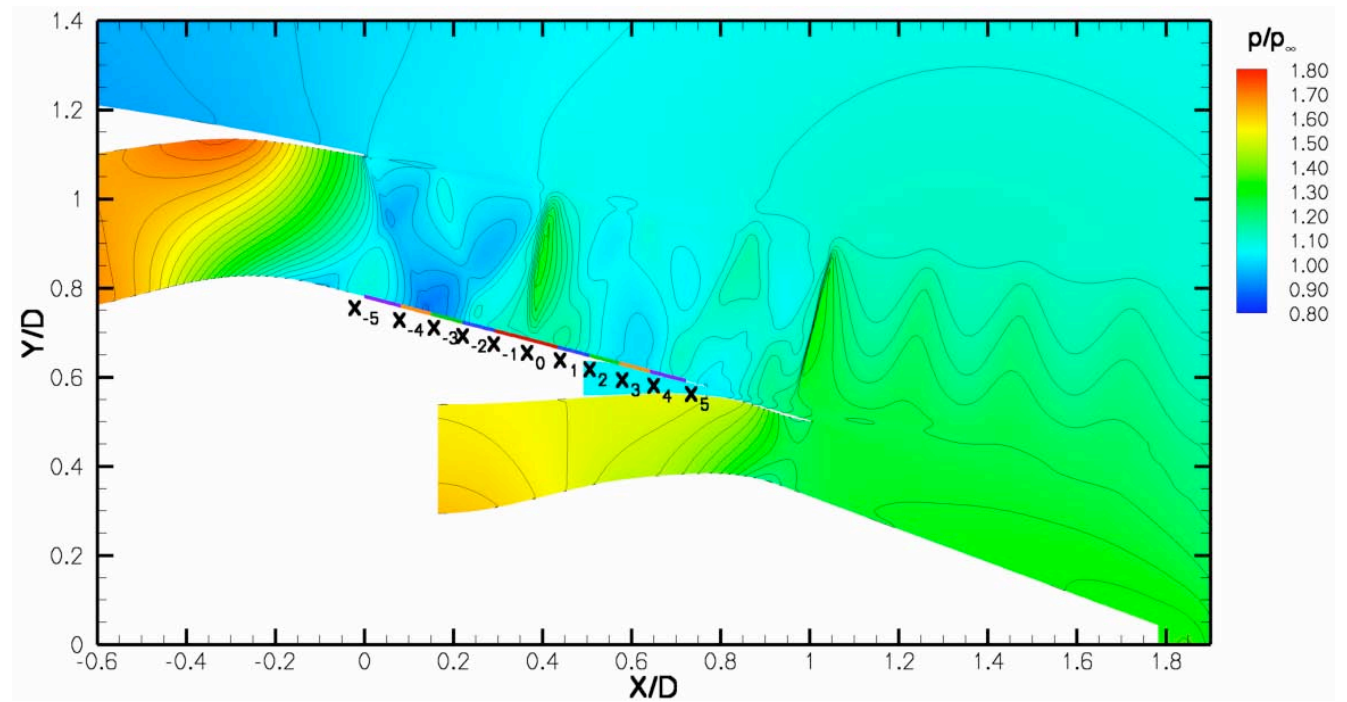

(b) Porous $x_{-1}$ to $x_{1}$

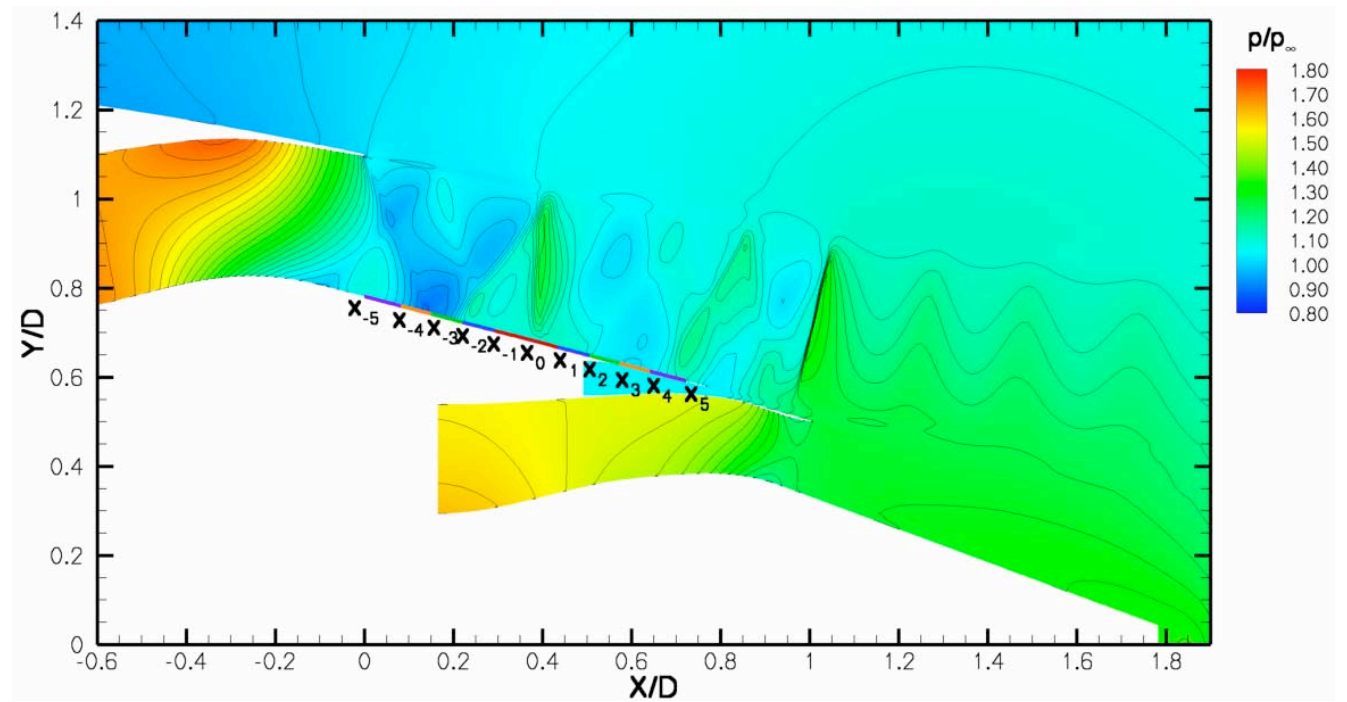

(c) Porous $x_{-2}$ to $x_{2}$

Figure 8. Normalized static pressure contours for increasing lengths of porosity. 


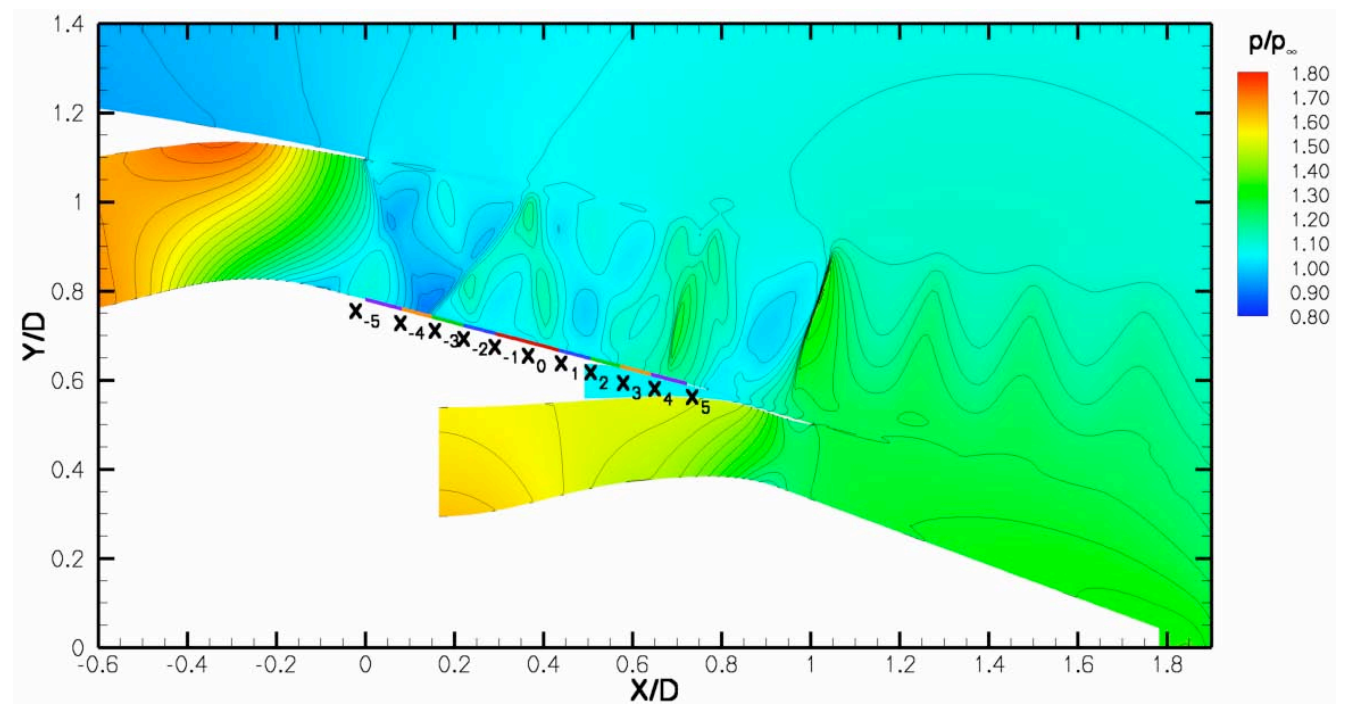

(a) Porous $x_{-3}$ to $x_{3}$

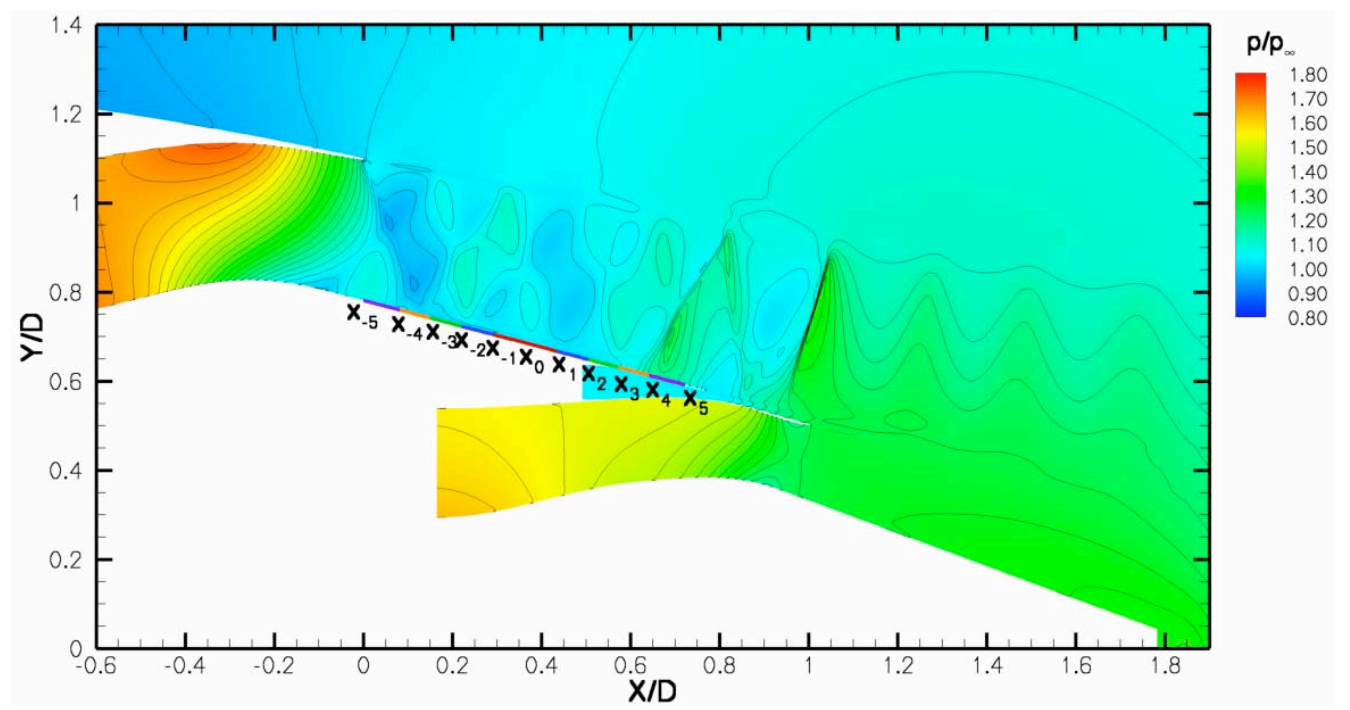

(b) Porous $x_{-4}$ to $x_{4}$

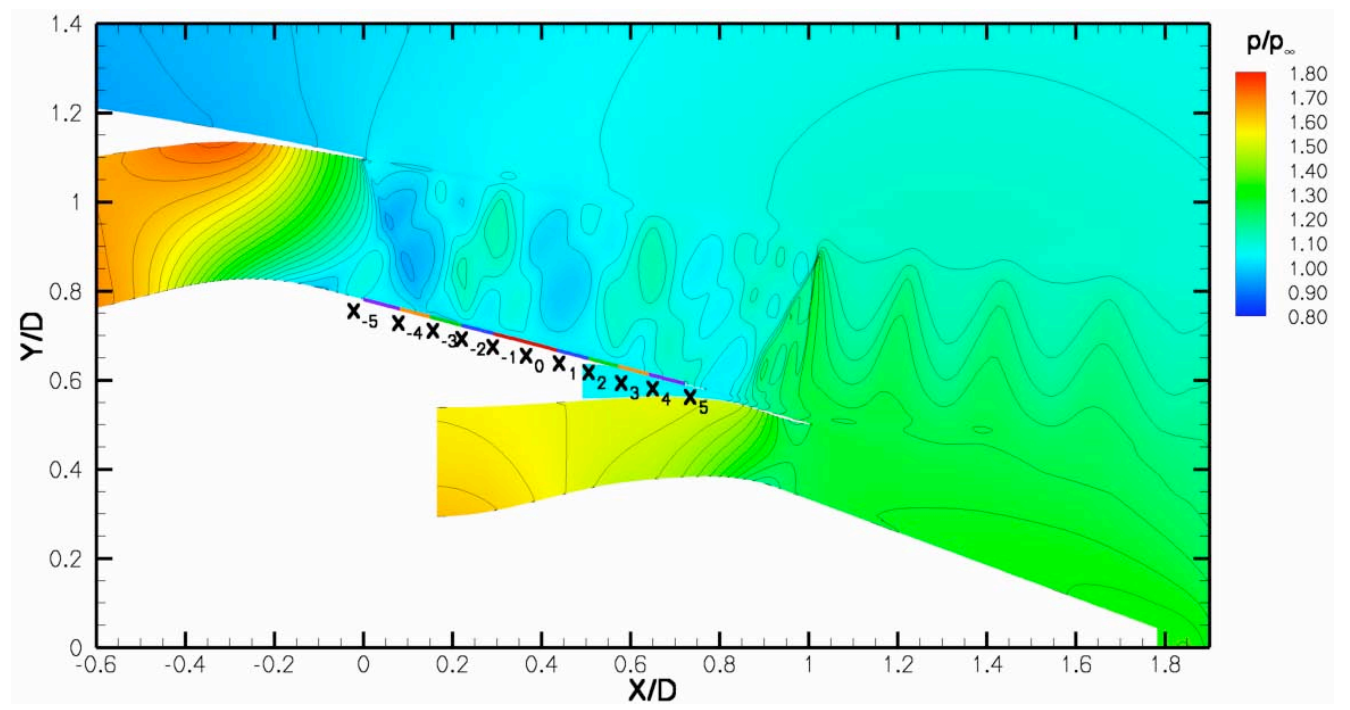

(c) Porous $x_{-5}$ to $x_{5}$

Figure 9. Normalized static pressure contours for increasing lengths of porosity. 


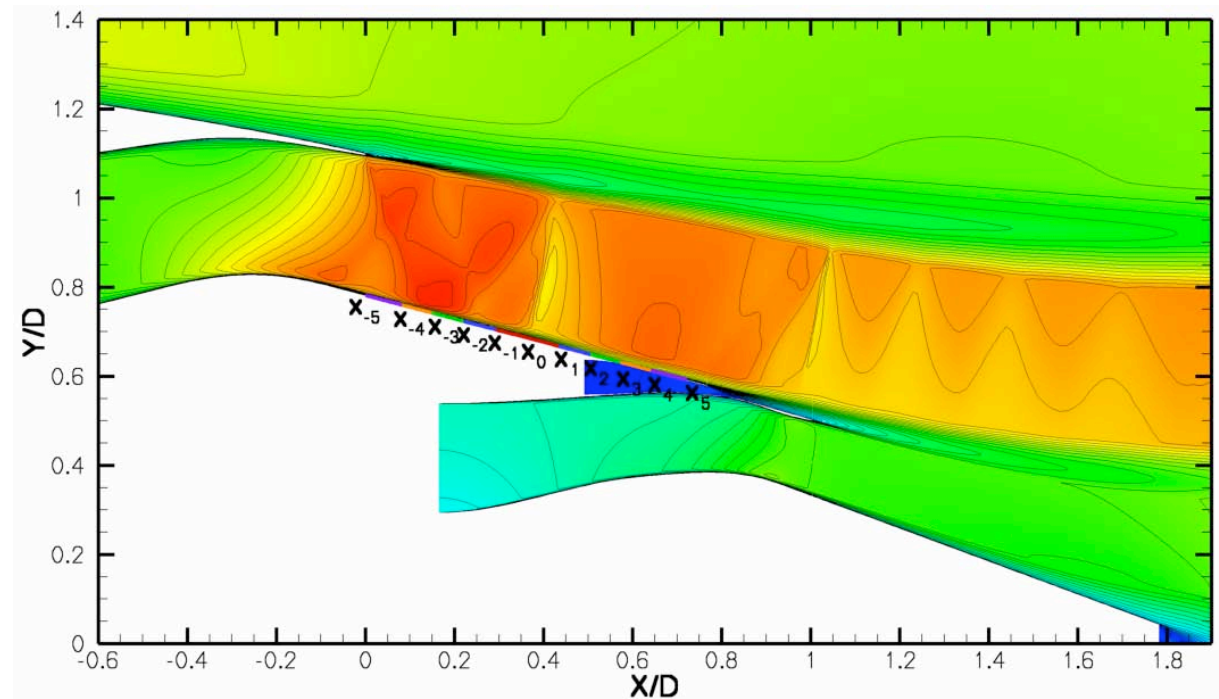

\begin{tabular}{c} 
Mach \\
1.22 \\
1.12 \\
1.02 \\
0.92 \\
0.82 \\
0.72 \\
0.62 \\
0.52 \\
0.42 \\
0.32 \\
0.22 \\
0.12 \\
0.02 \\
\hline
\end{tabular}

(a) Solid

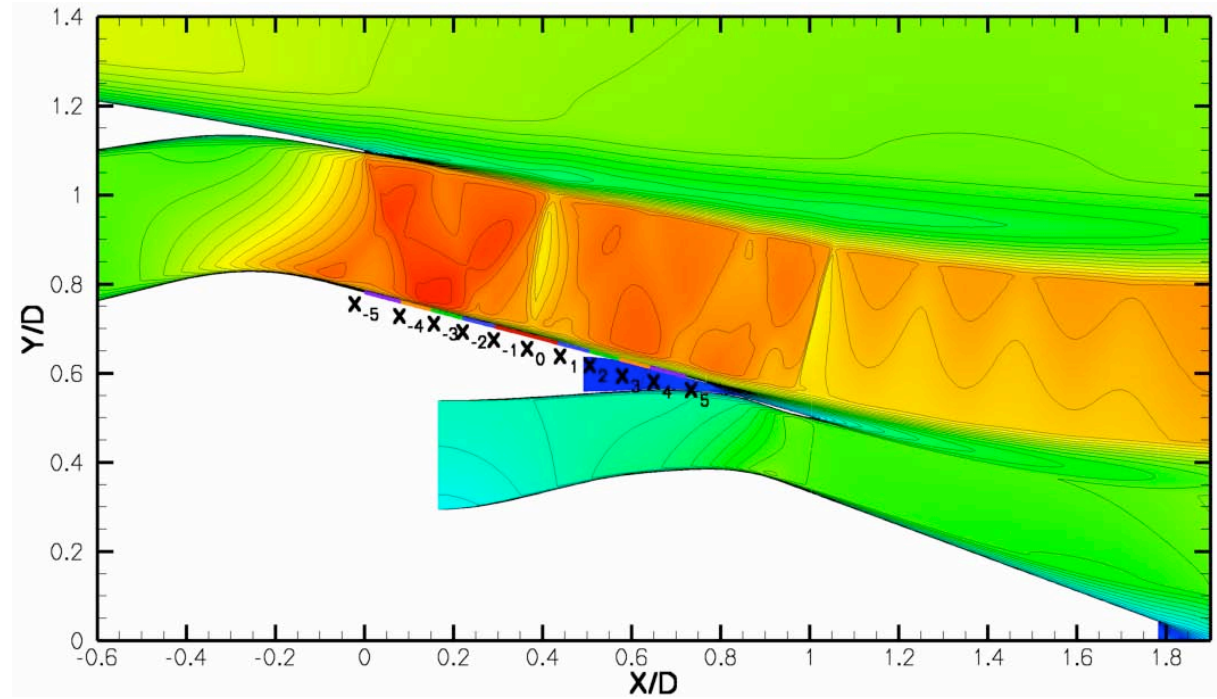

Mach

1.22
1.12
1.02
0.92
0.82
0.72
0.62
0.52
0.42
0.32
0.22
0.12
0.02

(b) Porous $x_{-1}$ to $x_{1}$

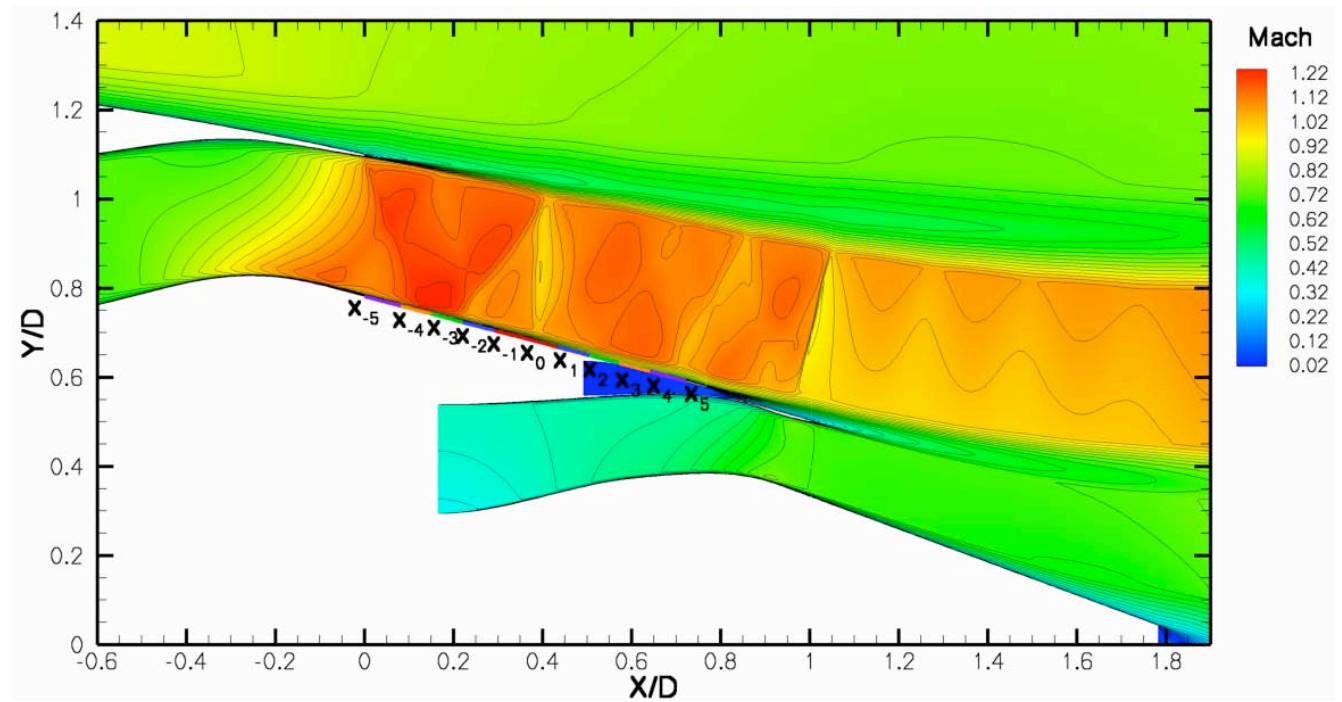

(c) Porous $x_{-2}$ to $x_{2}$

Figure 10. Mach contours for increasing lengths of porosity. 


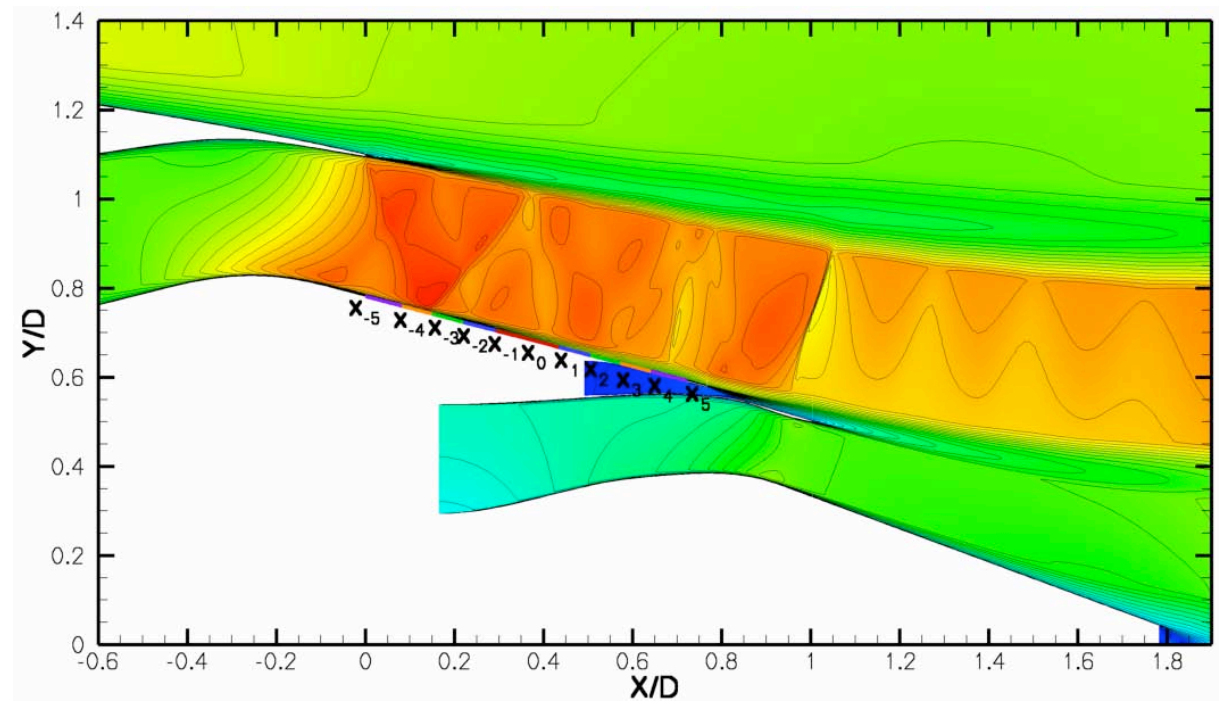

\begin{tabular}{c} 
Mach \\
1.22 \\
1.12 \\
1.02 \\
0.92 \\
0.82 \\
0.72 \\
0.62 \\
0.52 \\
0.42 \\
0.32 \\
0.22 \\
0.12 \\
0.02 \\
\hline
\end{tabular}

(a) Porous $x_{-3}$ to $x_{3}$

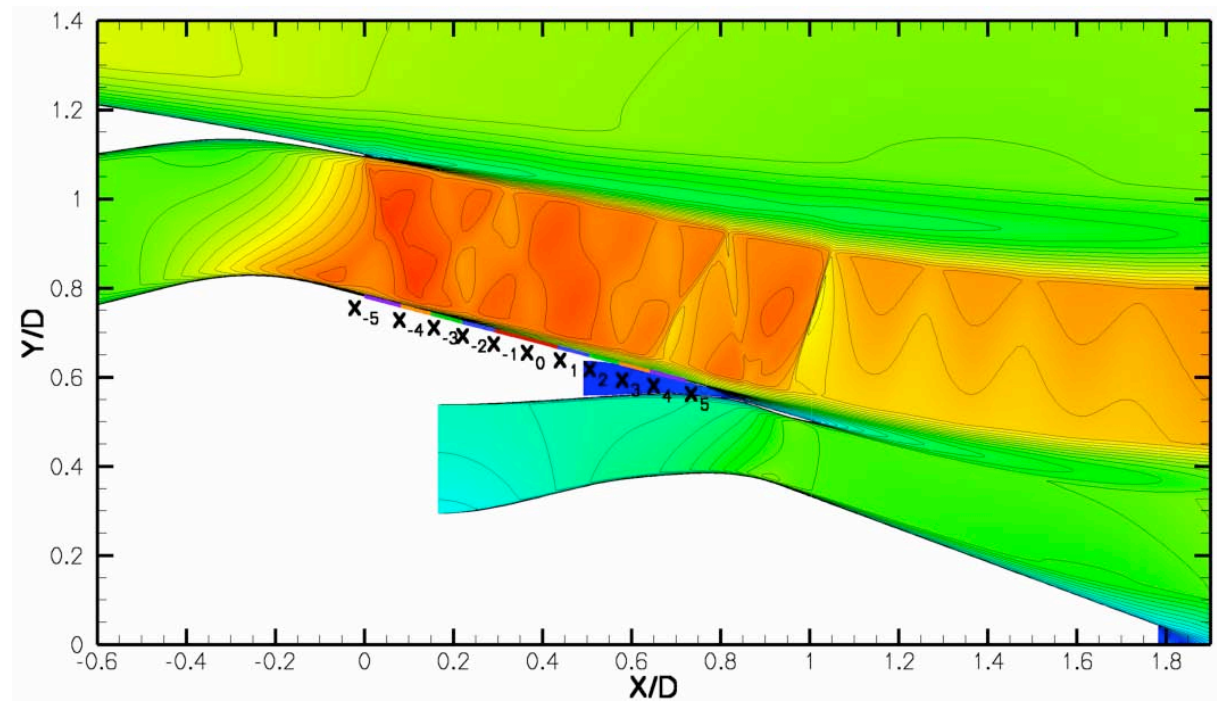

Mach

(b) Porous $x_{-4}$ to $x_{4}$

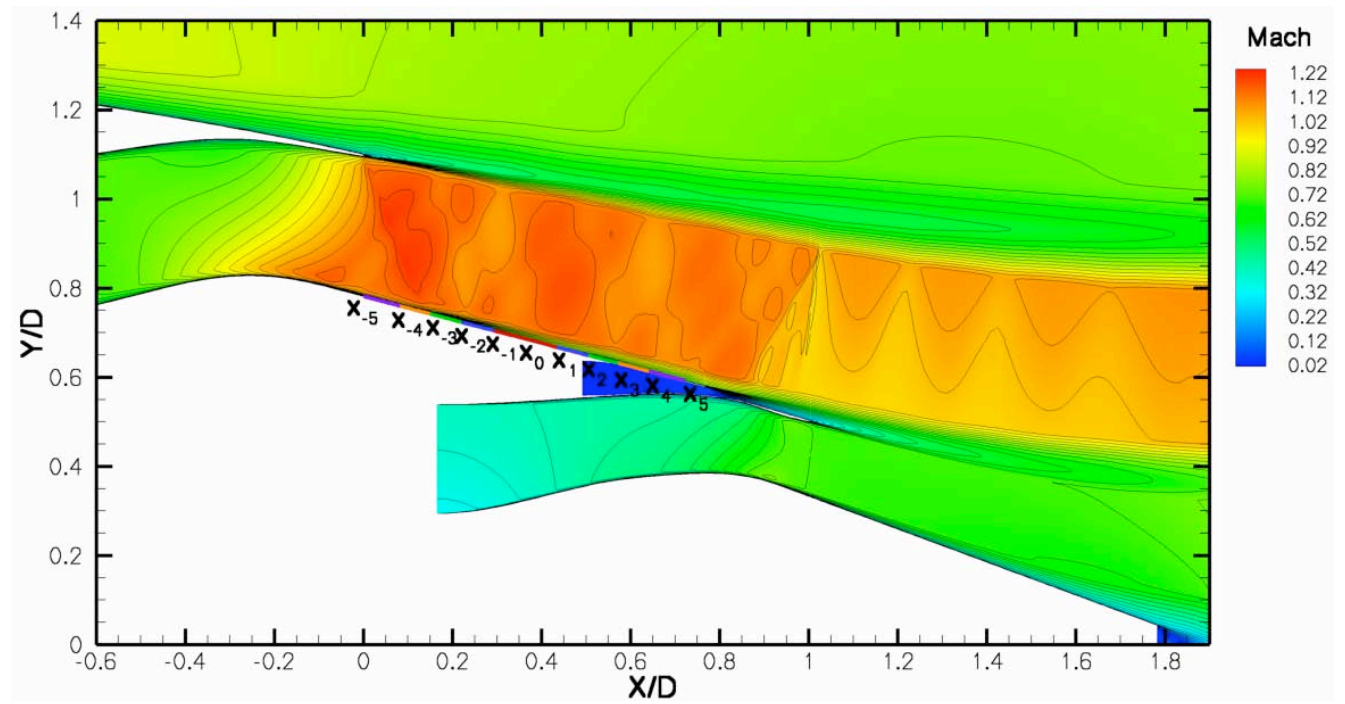

(c) Porous $x_{-5}$ to $x_{5}$

Figure 11. Mach contours for increasing lengths of porosity. 


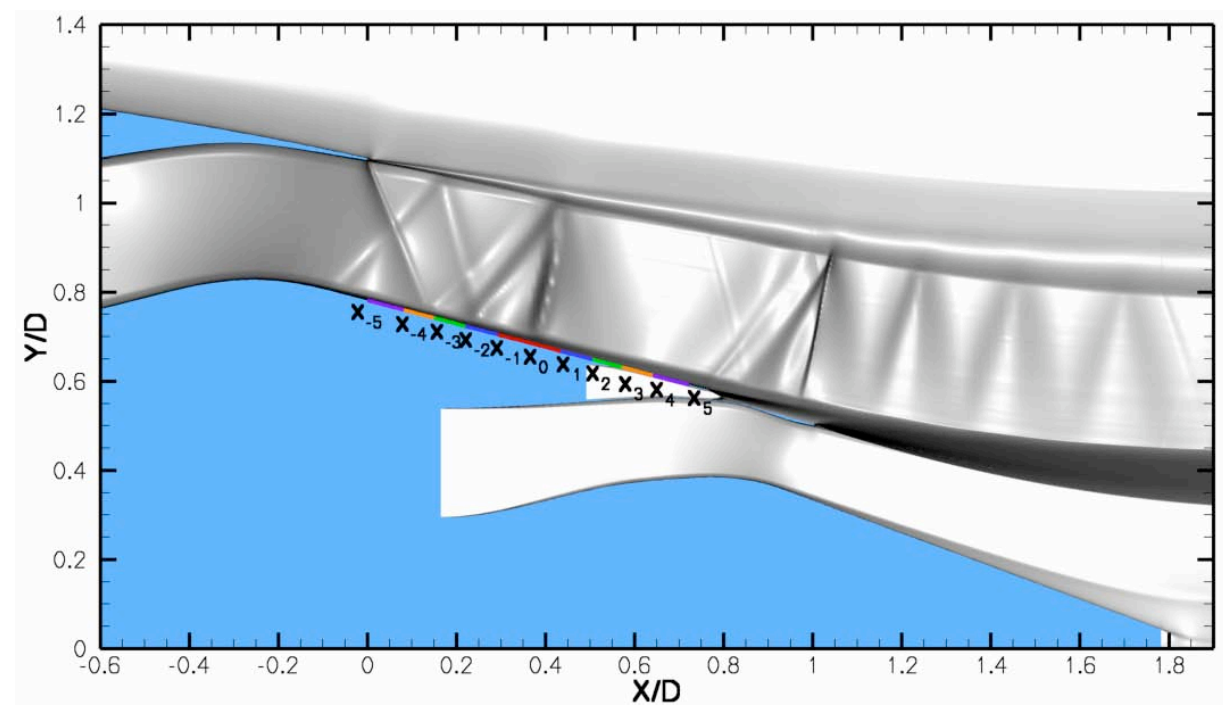

(a) Solid

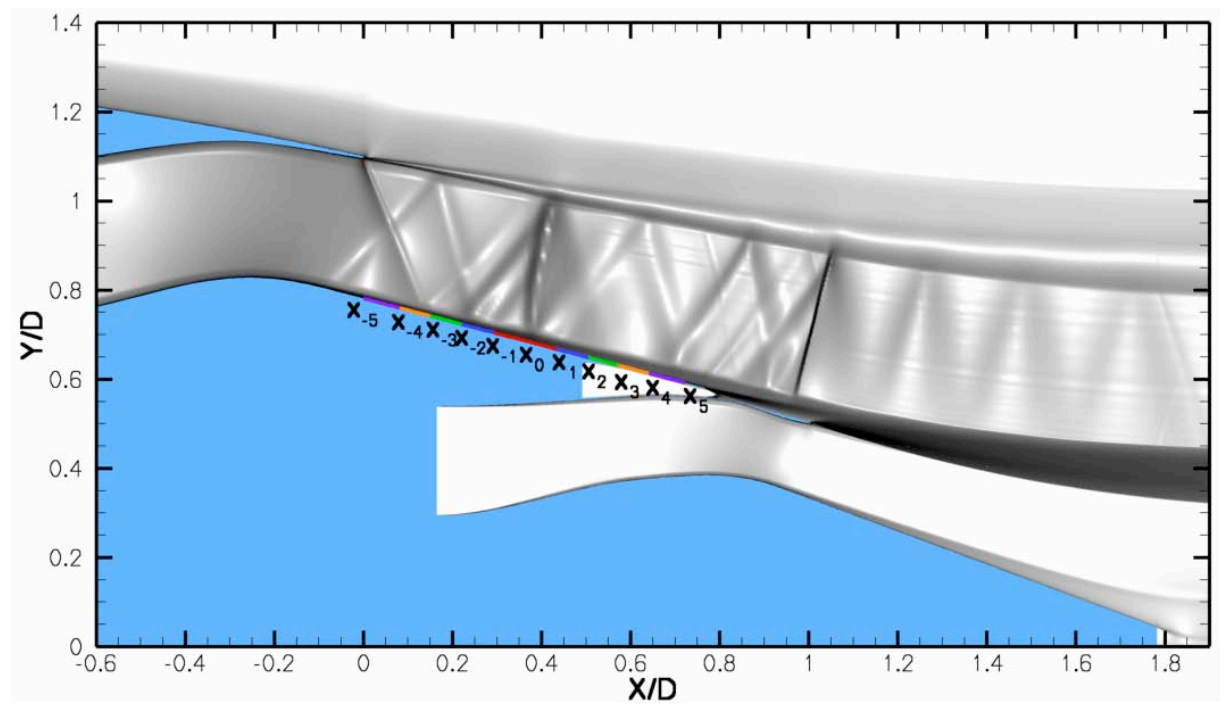

(b) Porous $x_{-1}$ to $x_{1}$

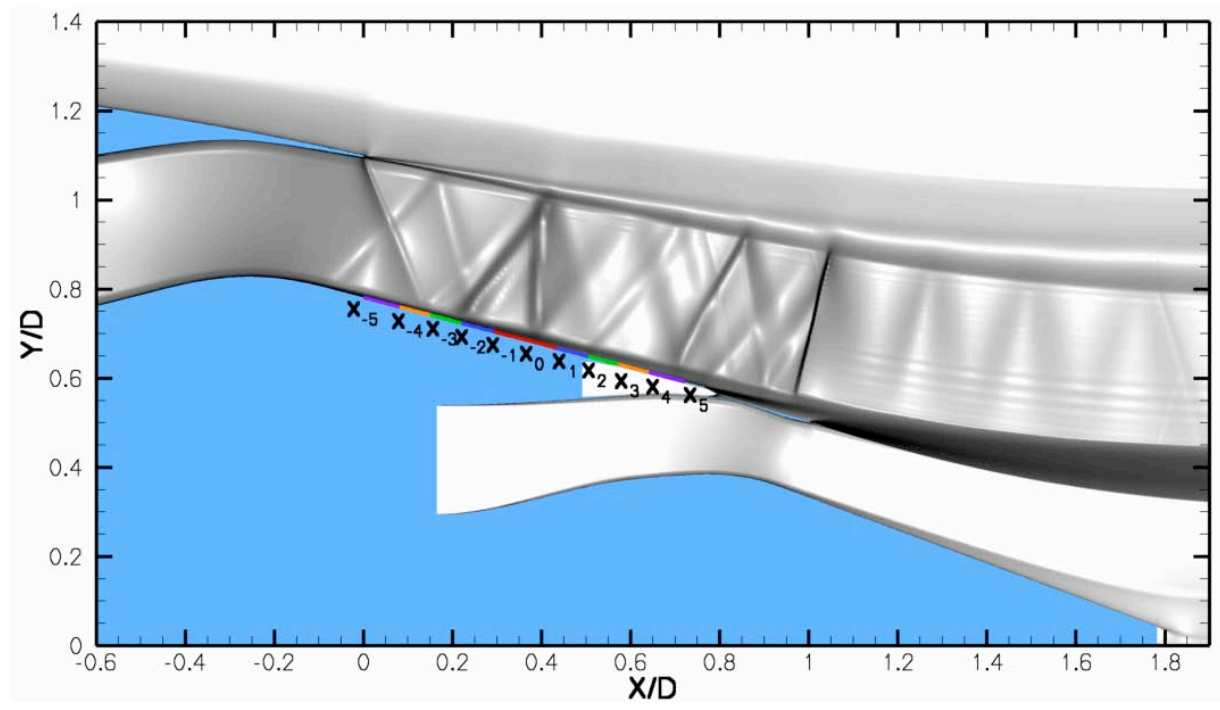

(c) Porous $x_{-2}$ to $x_{2}$

Figure 12. Simulated Schlieren contours for increasing lengths of porosity. 


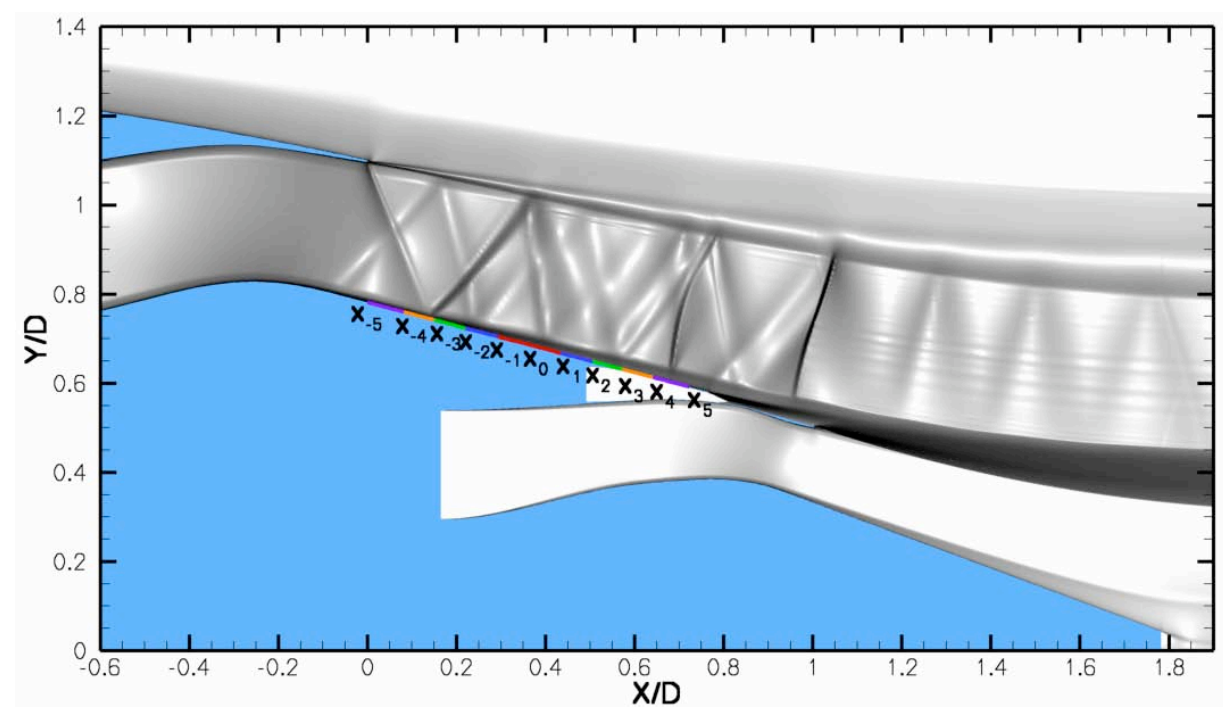

(a) Porous $x_{-3}$ to $x_{3}$

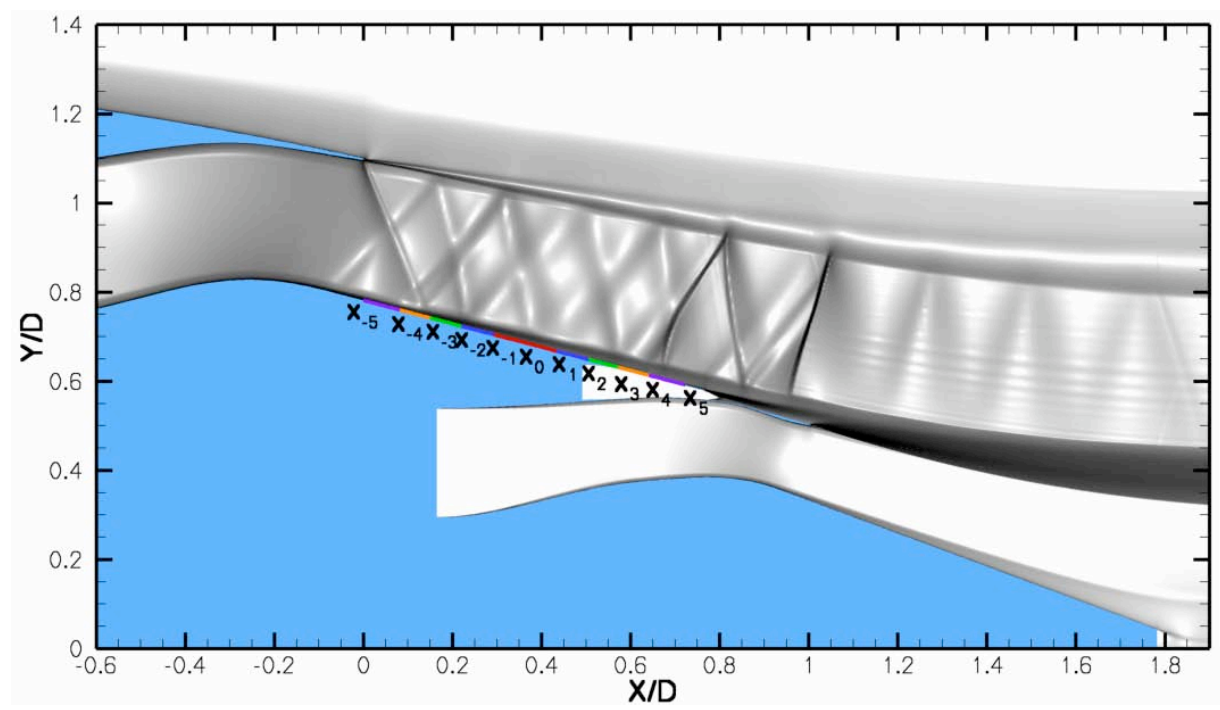

(b) Porous $x_{-4}$ to $x_{4}$

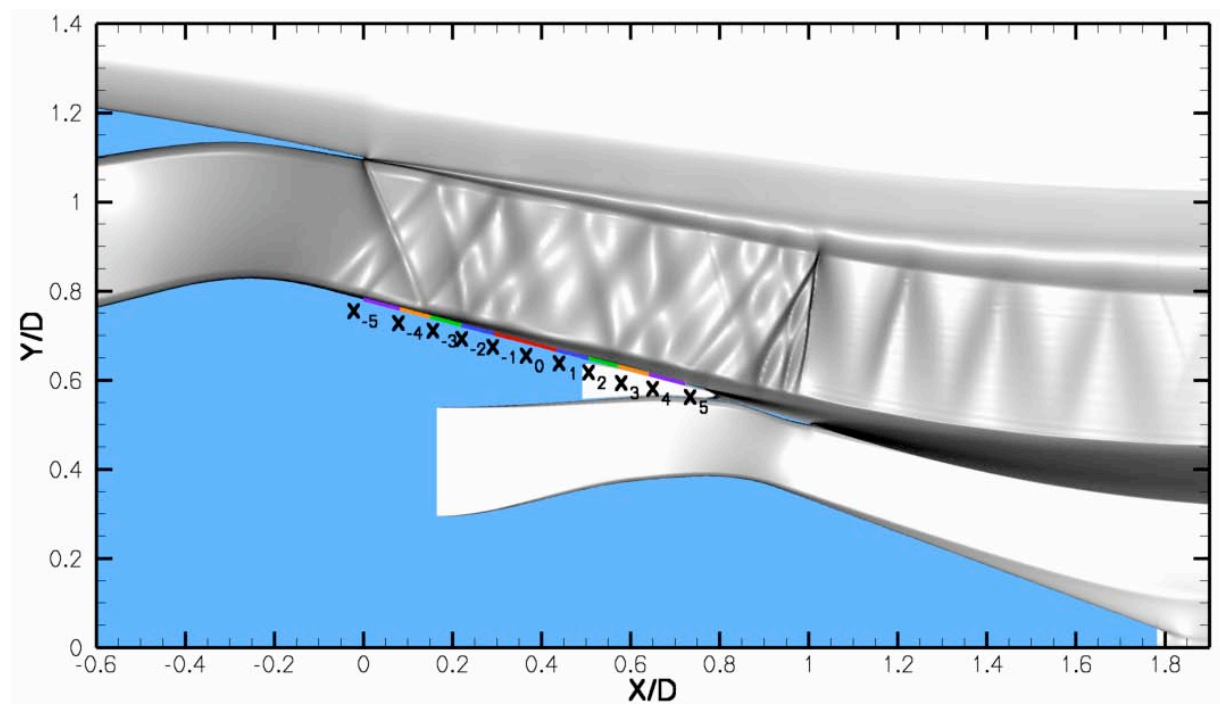

(c) Porous $x_{-5}$ to $x_{5}$

Figure 13. Simulated Schlieren contours for increasing lengths of porosity. 


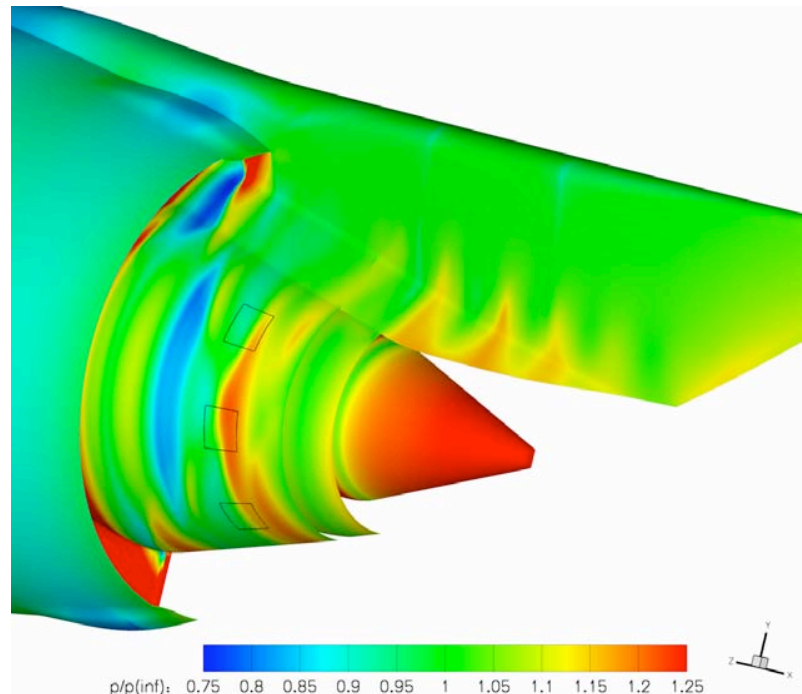

(a) Baseline Solid

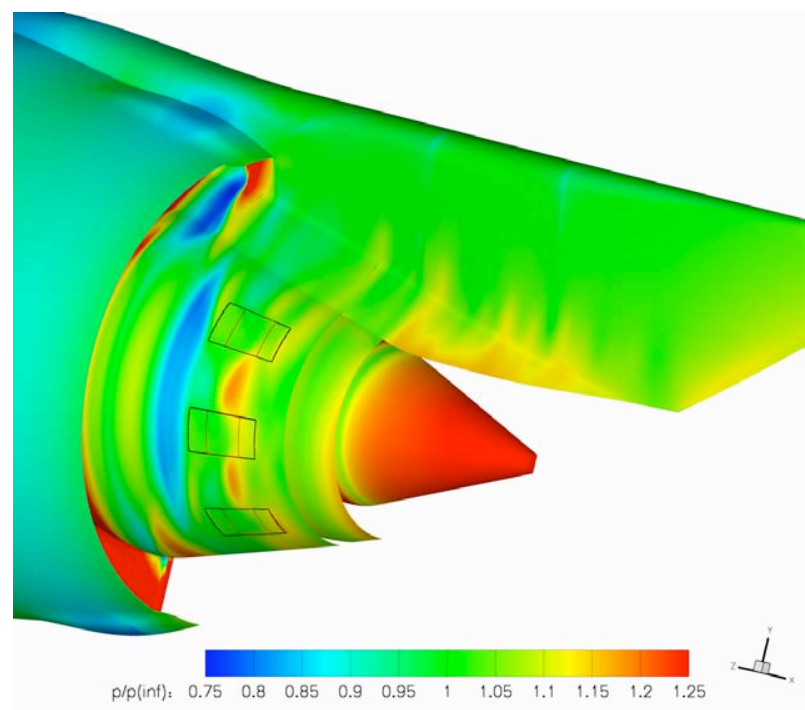

(c) Long Porous Patches

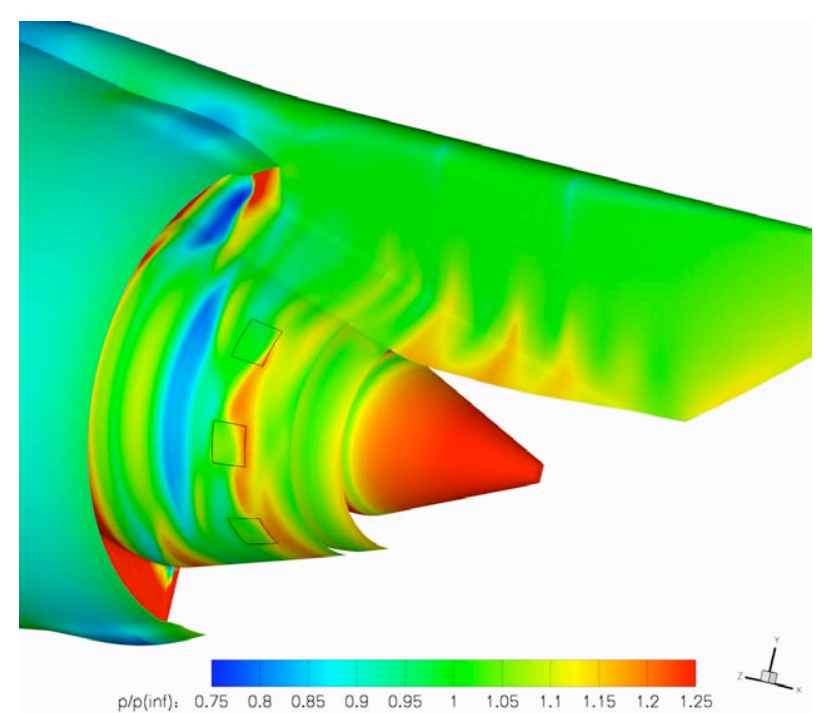

(b) Baseline Porous Patches

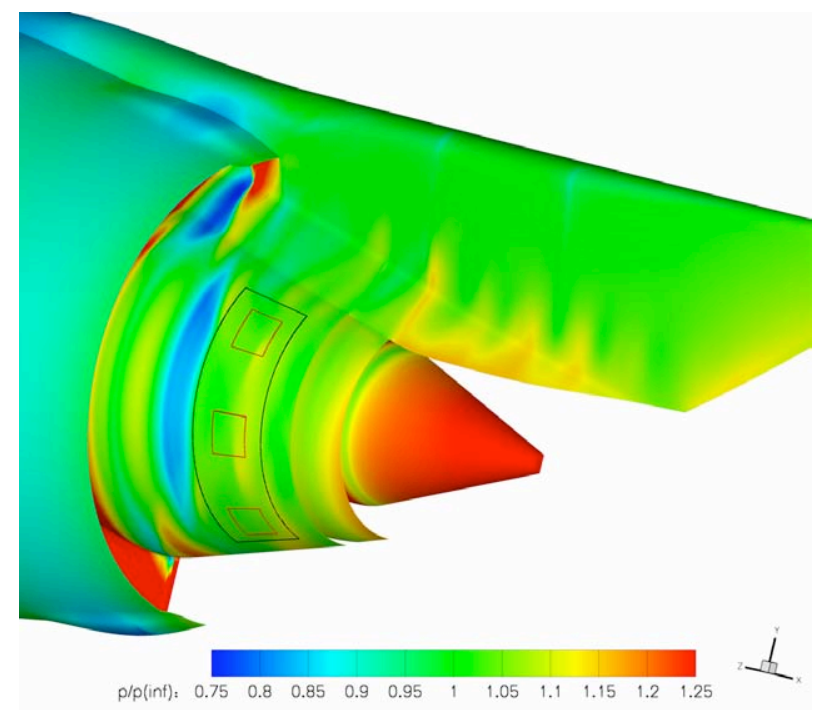

(d) Long Porous Strip

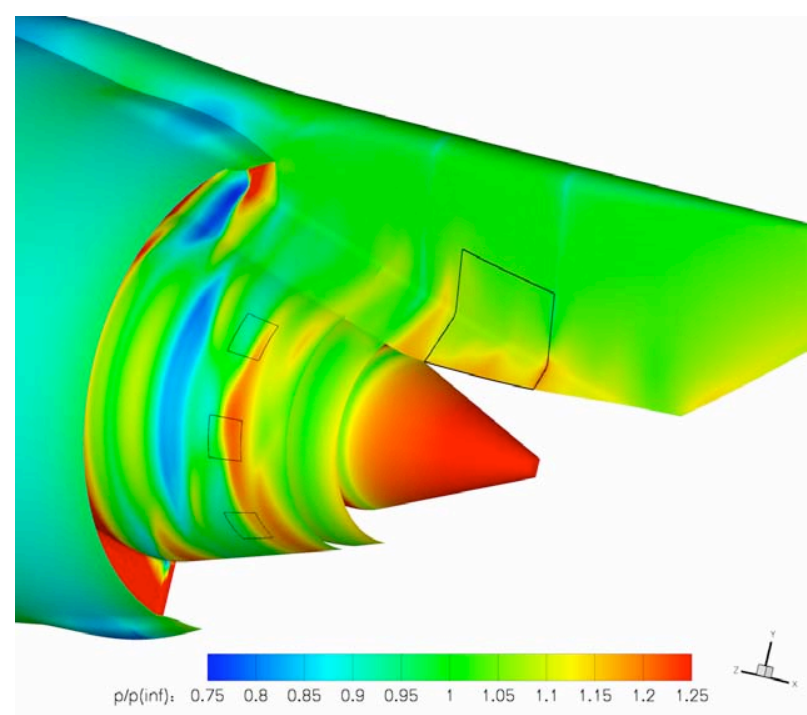

(e) Porous Pylon

Figure 14. Surface pressure contours, with porous patches outlined together with baseline porous patch outline. 


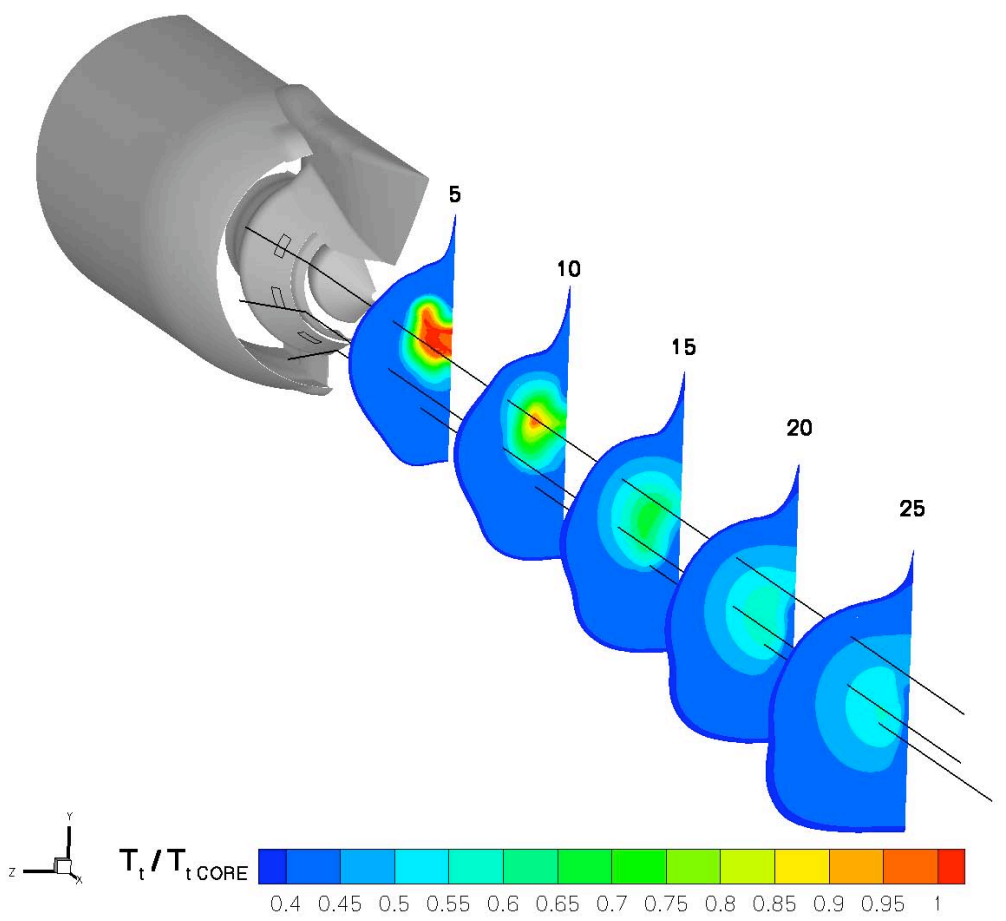

(a) Total temperature

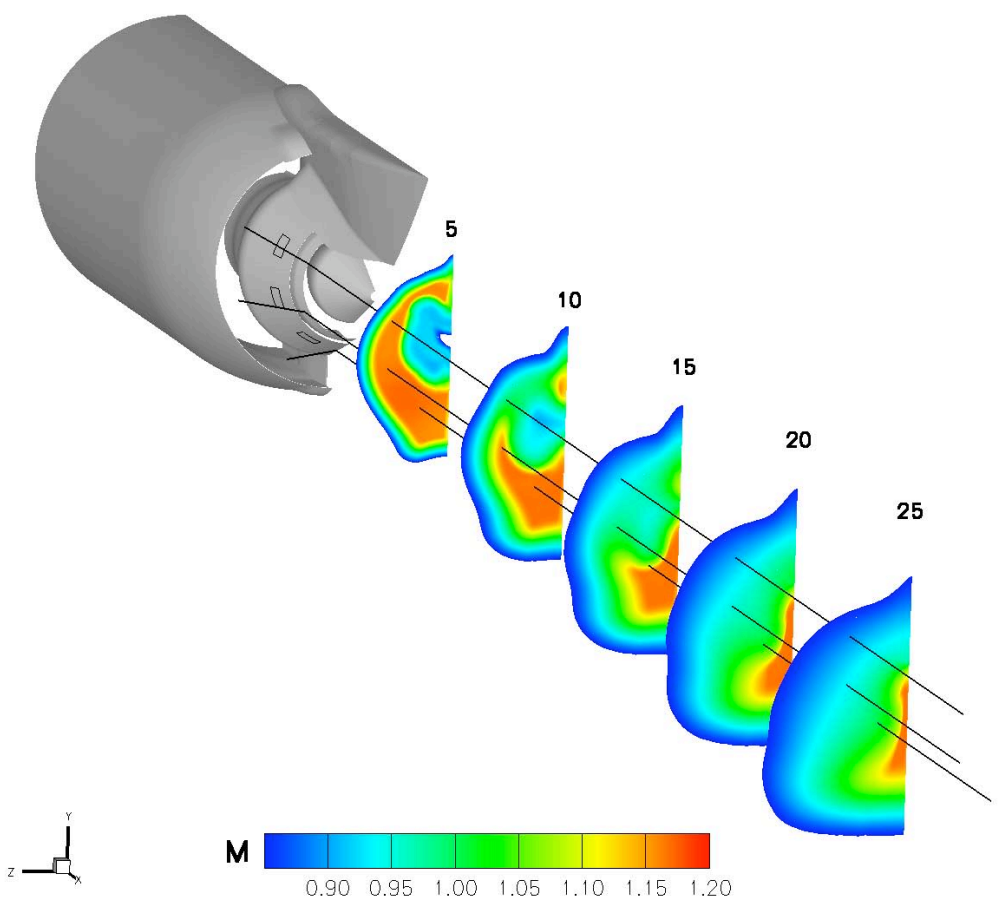

(b) Local Mach number

Figure 15. Baseline Solid Surface: Total temperature and local Mach number contours on crossflow planes at increments of five core diameters. Black lines indicate line data extraction locations. 


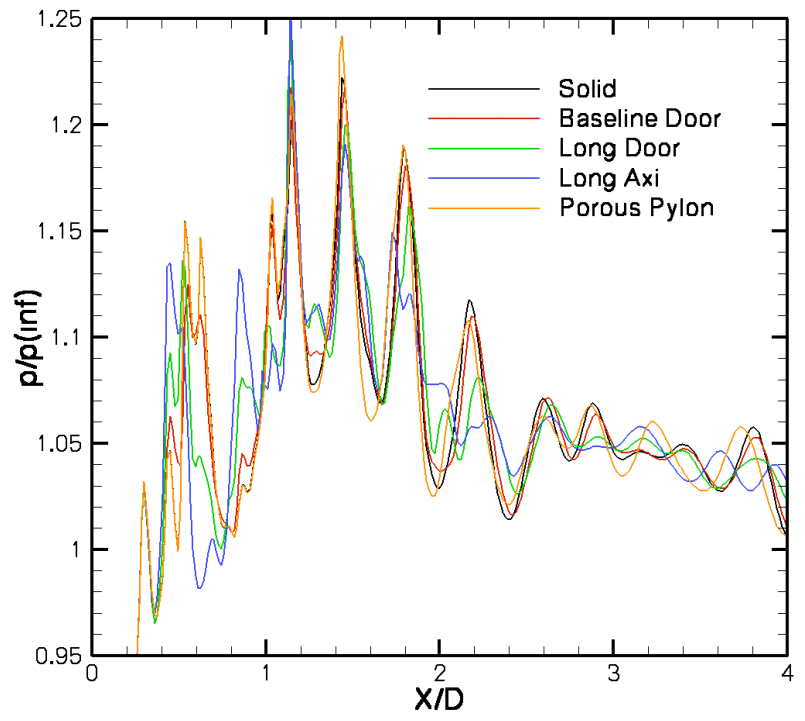

(a) Top: $0 \leq X / D \leq 4$

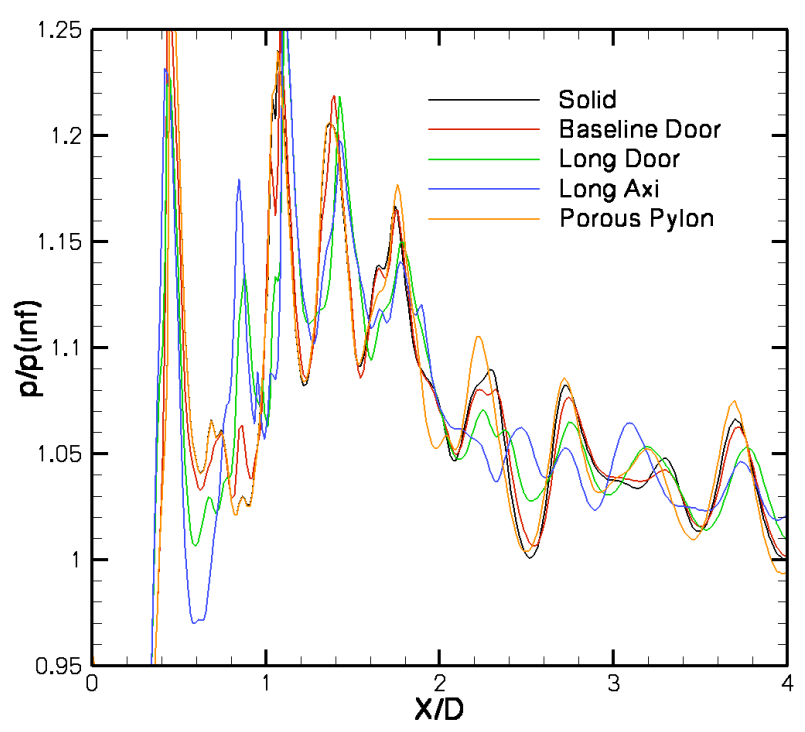

(c) Middle: $0 \leq X / D \leq 4$

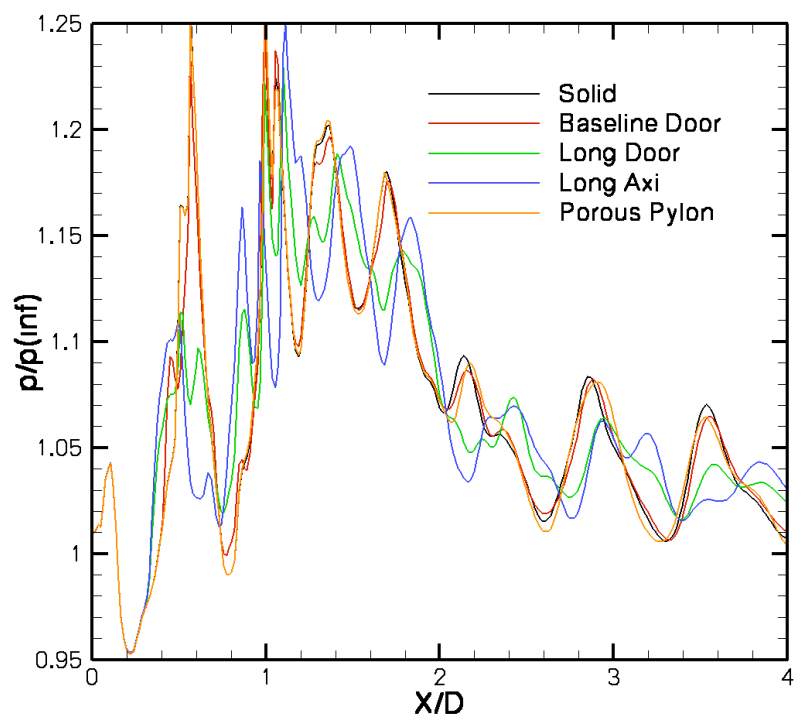

(e) Bottom: $0 \leq X / D \leq 4$

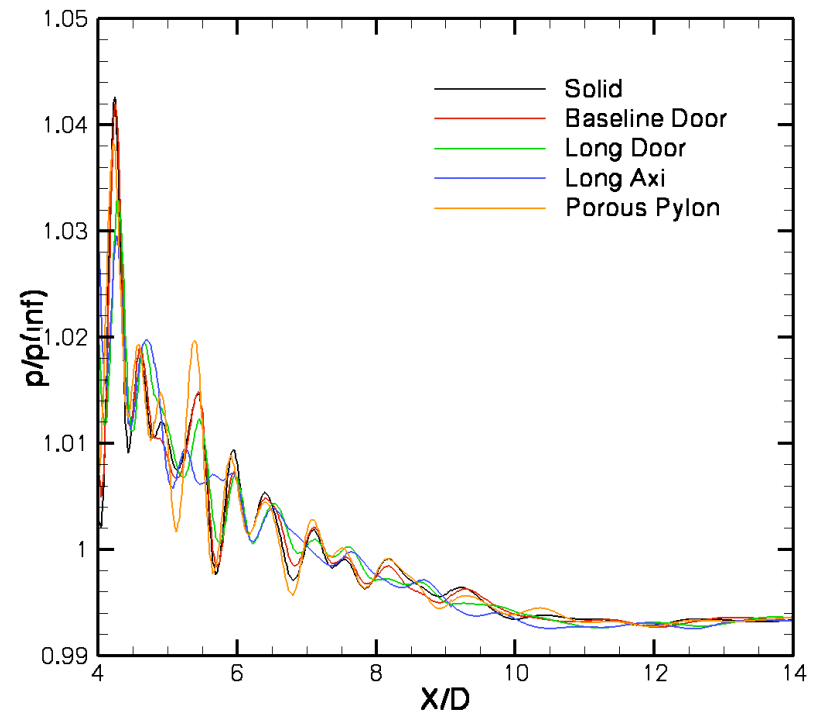

(b) Top: $4 \leq X / D \leq 14$

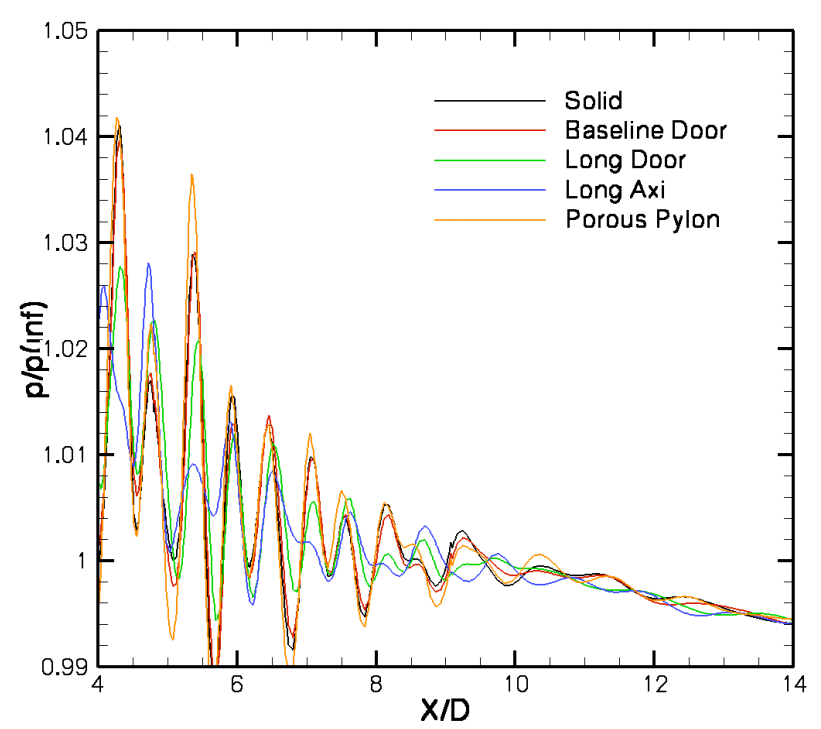

(d) Middle: $4 \leq X / D \leq 14$

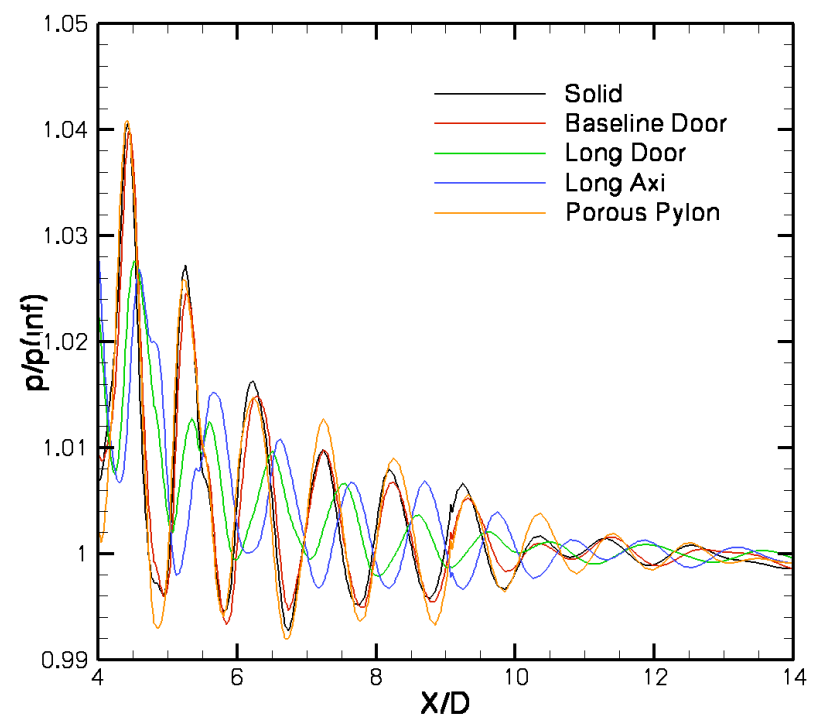

(f) Bottom: $4 \leq X / D \leq 14$

Figure 16. Normalized static pressure traces in fan stream at three azimuthal stations. 


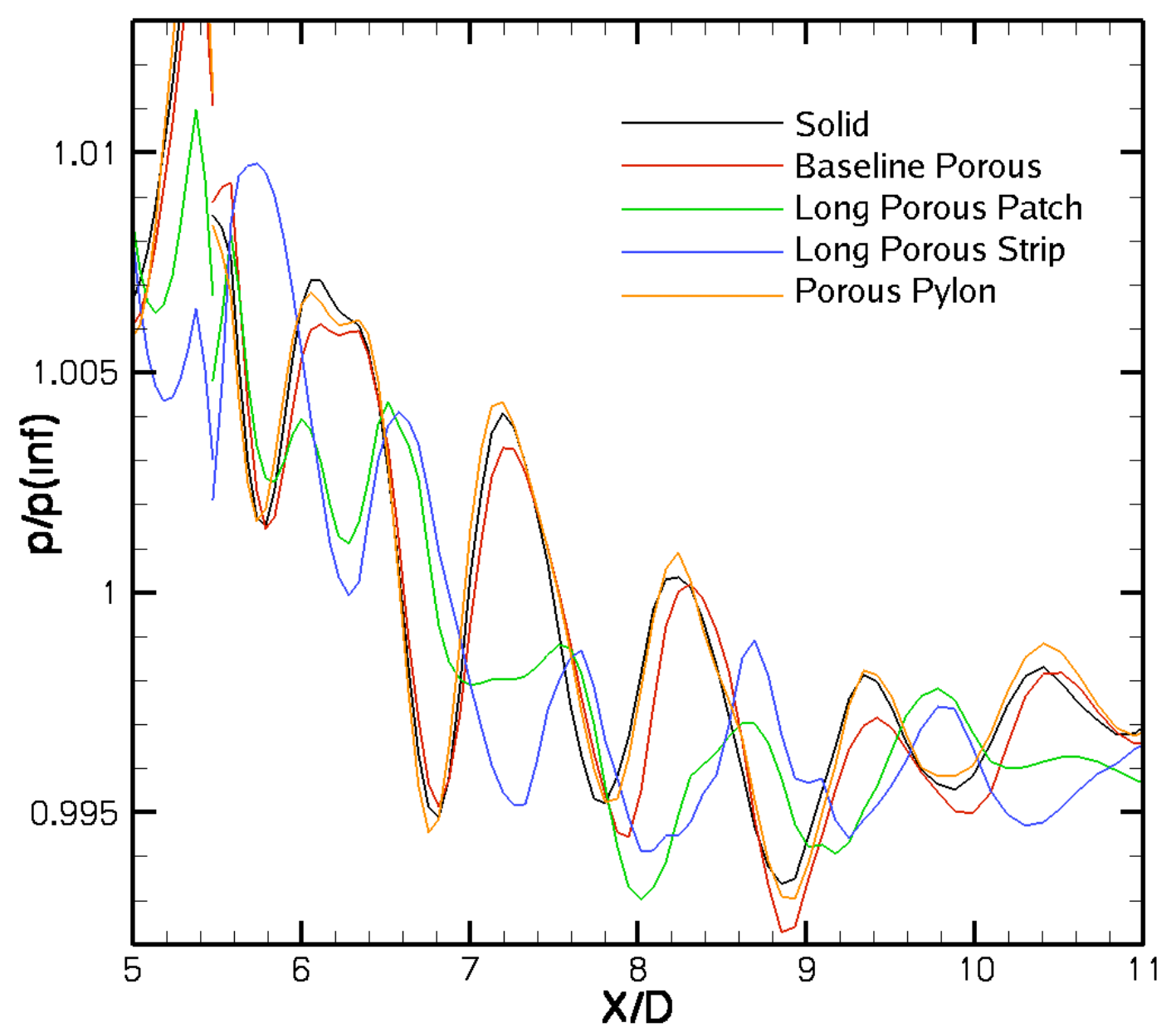

Figure 17. Pressure along centerline of jet for each of the porous configurations. 